Check for updates

Cite this: RSC Adv., 2018, 8, 26728

\title{
MOF derived carbon based nanocomposite materials as efficient electrocatalysts for oxygen reduction and oxygen and hydrogen evolution reactions
}

\author{
Sohini Bhattacharyya, (iD Chayanika Das and Tapas Kumar Maji (DD*
}

The escalating global energy demands and the formidable risks posed by fossil fuels coupled with their rapid depletion have inspired researchers to embark on a quest for sustainable clean energy. Electrochemistry based technologies, e.g., fuel cells, Zn-air batteries or water splitting, are some of the frontrunners of this green energy revolution. The primary concern of such sustainable energy technologies is the efficient conversion and storage of clean energy. Most of these technologies are based on half-cell reactions like oxygen reduction, oxygen and hydrogen evolution reactions, which in turn depend on noble metal based catalysts for their efficient functioning. In order to make such green energy technologies economically viable, the need of the hour is to develop new noble metal free catalysts. Porous carbon, with some assistance from heteroatoms like $\mathrm{N}$ or $\mathrm{S}$ or earth abundant transition metal or metal oxide nanoparticles, has shown excellent potential in the catalysis of such electrochemical reactions. Metal-organic frameworks (MOFs) containing metal nodes and organic linkers in an ordered morphology with inherent porosity are ideal self-sacrificial templates for such carbon materials. There has been a recent spurt in reports on such MOF-derived carbon based materials as electrocatalysts. In this review, we have presented some of this research work and also discussed the practical reasons behind choosing MOFs for this purpose. Different approaches for synthesizing such carbonaceous materials with unique morphologies and doping, targeted towards superior electrochemical activity, have been documented in this review.

\begin{abstract}
Received 13th June 2018 Accepted 16th July 2018 DOI: 10.1039/c8ra05102j rsc.li/rsc-advances
\end{abstract}

\section{Introduction}

The rapid progress in technology and industrialization has caused an enormous increase in global energy requirement. To date, the world relies almost entirely on non-renewable fossil

Molecular Materials Laboratory, Chemistry and Physics of Materials Unit, School of Advanced Materials (SAMat), Jawaharlal Nehru Centre for Advanced Scientific Research (JNCASR), Bangalore, India.E-mail: tmaji@jncasr.ac.in

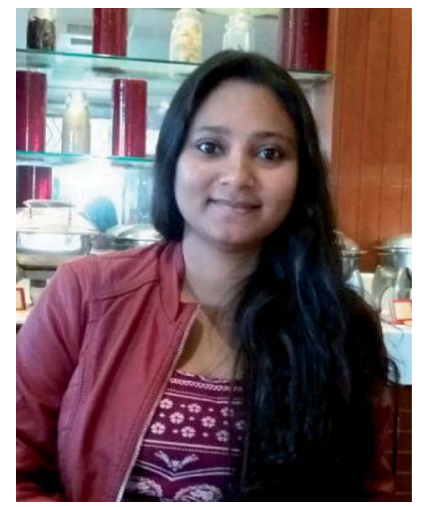

Chayanika Das obtained her B.Sc degree from St. Xavier's College, Kolkata in 2008, after which she completed her M.Sc from Banaras Hindu University, Varanasi, in 2010. She completed her PhD from National Chemical Laboratories, Pune, in 2017 on energy storage in surface modified substrates. She is currently a Post-doctoral fellow in Prof. Tapas K. Maji's group. Her research interests comprise electrochemical applications of porous materials. and post-synthetic modification of MOFs. 
fuels to cater to the daily energy requirements. ${ }^{1}$ However, the immense adverse effects caused by these fossil fuels on the environment in the form of global warming as well as their swift depletion rates makes it essential for us to regulate their use immediately. ${ }^{2-4}$ Thus the world is in the process of a gradual shift towards a renewable energy based economy, namely solar, wind, and hydro power. ${ }^{-9}$ However, these sources do not always ensure a steady flow of power and are often sporadic in their outputs. The efficient usage of such sources thus requires effective assistance from conversion and storage technologies such as fuel cells, batteries and capacitors. ${ }^{10-19}$ Fuel cells and metal-air batteries are typical representatives of energy conversion and storage systems with high energy density, high efficiency and no greenhouse emissions..$^{20-33}$ The competence of these devices is primarily determined by the functional materials used as electrocatalysts in their components. Thus the major concern of scientists worldwide is the development of cost and energy efficient sustainable electrocatalysts for better conversion, storage and utilization of renewable energy. While fuel cells involves the combination of a steady stream of $\mathrm{O}_{2}$ at the cathode and $\mathrm{H}_{2}$ at the anode to form water, regenerative fuel cells rely on the reverse process of splitting water to generate $\mathrm{O}_{2}$ and $\mathrm{H}_{2} \cdot{ }^{18,32,34-38}$ The former is concerned mainly with oxygen reduction reaction (ORR) at the cathode and hydrogen oxidation reaction (HOR) at the anode, and the latter includes hydrogen and oxygen evolution reactions (HER and OER, respectively). Similarly, metal-air batteries perform OER while charging and ORR during discharging cycle..$^{20,22-25,30,31,39-45}$ Many of the above mentioned electrochemical reactions are extremely sluggish in nature, making the use of catalysts mandatory. However, the most efficient catalysts for these processes are often expensive and scarce noble metals like Pt, Ir and $\mathrm{Ru}^{\mathbf{4 5 - 6 1}}$ The exorbitant prices of these metals are the biggest obstacles hindering the widespread commercialization of electrochemical process dependant energy technologies. Hence one of the biggest challenges of the materials science world currently

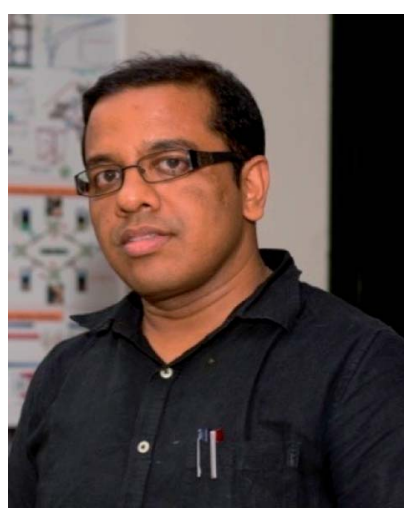

Tapas Kumar Maji obtained his PhD in 2002 from the Indian Association for the Cultivation of Science (IACS), Kolkata. After a postdoctoral stint at Kyoto University with Prof. Susumu Kitagawa, he joined Jadavpur University. Then he moved to the Jawaharlal Nehru Centre for Advanced Scientific Research (JNCASR), Bangalore. Currently, he is a professor in the Chemistry and Physics of Materials Unit at

JNCASR. His current research interest focuses on the design and synthesis of functional bulk and nanoscale metal-organic frameworks (MOFs) and organic porous polymers for energy-storage and generation, carbon capture and sequestration. He also works on different photo-physical aspects of MOFs and coordination polymer gels. Prof. Maji has published over 190 peer-reviewed publications. involves the development of low-cost, sustainable, energy efficient functional materials that can compete with these noble metals in their activity and thereby replace them. The alternative materials envisaged for this purpose are carbon based materials or benign earth abundant metal based counterparts. ${ }^{27-29,57-75}$ An absolute necessity in these materials is the presence of easily accessible redox-active centres, that will trap the particular element and reduce them promptly. Hence redox active, semiconducting, porous materials like MOFs, COFs or CMPs seem to be the ideal candidates for such catalysis. ${ }^{64,124,166,167}$ Among the cost-effective catalysts explored in recent times, porous carbon materials have emerged as one of the flag bearers owing to their stability, high conductivity, excellent surface area, tunable porosity and surface chemistry. ${ }^{64}$ A few recent reports have also exhibited the efficacy of doping heteroatoms (e.g., N, S and B) in a porous carbon matrix in elevating electrocatalytic activity. These heteroatoms are present in the carbon matrix as defects and brings about electronic and structural modifications (Scheme 1). ${ }^{65-75}$

One of the most celebrated functional materials of the past decade has been Metal-organic frameworks (MOFs) comprising ordered arrays of metal nodes connecting organic linkers. ${ }^{76-79}$ MOFs have clinched the attention of chemists owing to their light weight, low density, ultra high surface area, porosity and tunable pore surface. Traditionally, MOFs have found application in gas separation, storage and capture of specific molecules. ${ }^{\mathbf{8 0 - 8 5}}$ They have also been utilized for catalysis, sensing and for various optoelectronic applications. ${ }^{85-90}$ Of late, MOFs and their derivatives have been explored as electrocatalysts. MOFs, owing to their innate porosity, large carbon content and ordered structures are the ideal templates for porous carbon based materials. Many of the recent research work on electrocatalysis have upheld MOFs and their derived materials as efficient electrocatalysts. In this review, we have documented some of them which stand out and establish that the tailored synthesis of MOFs and their derived materials can provide some of the best materials for electrocatalysis. For this purpose, we have first discussed the design principles of such materials, followed by their activity in common electrochemical processes, e.g., ORR, HER, OER and also bifunctional activity. The systematic arrangement in this review will hopefully be helpful to researchers working in this field and in the future it will help towards the development of supreme MOF-derived carbon based electrocatalysts.

\section{Why MOFs as templates for porous carbon based electrocatalysts?}

Taking a step away from the conventional applications of MOFs, e.g., storage and separation of gases, drug delivery, magnetism and optoelectronics, recent research has been aimed at designing MOF based electrocatalysts. The easily tunable pore structures and accessible metal nodes are the biggest advantages of using MOFs as electrocatalysts. The permanent porosity of MOFs helps in the swift diffusion of substrates throughout the material, thus helping the substrates reach catalytic sites 

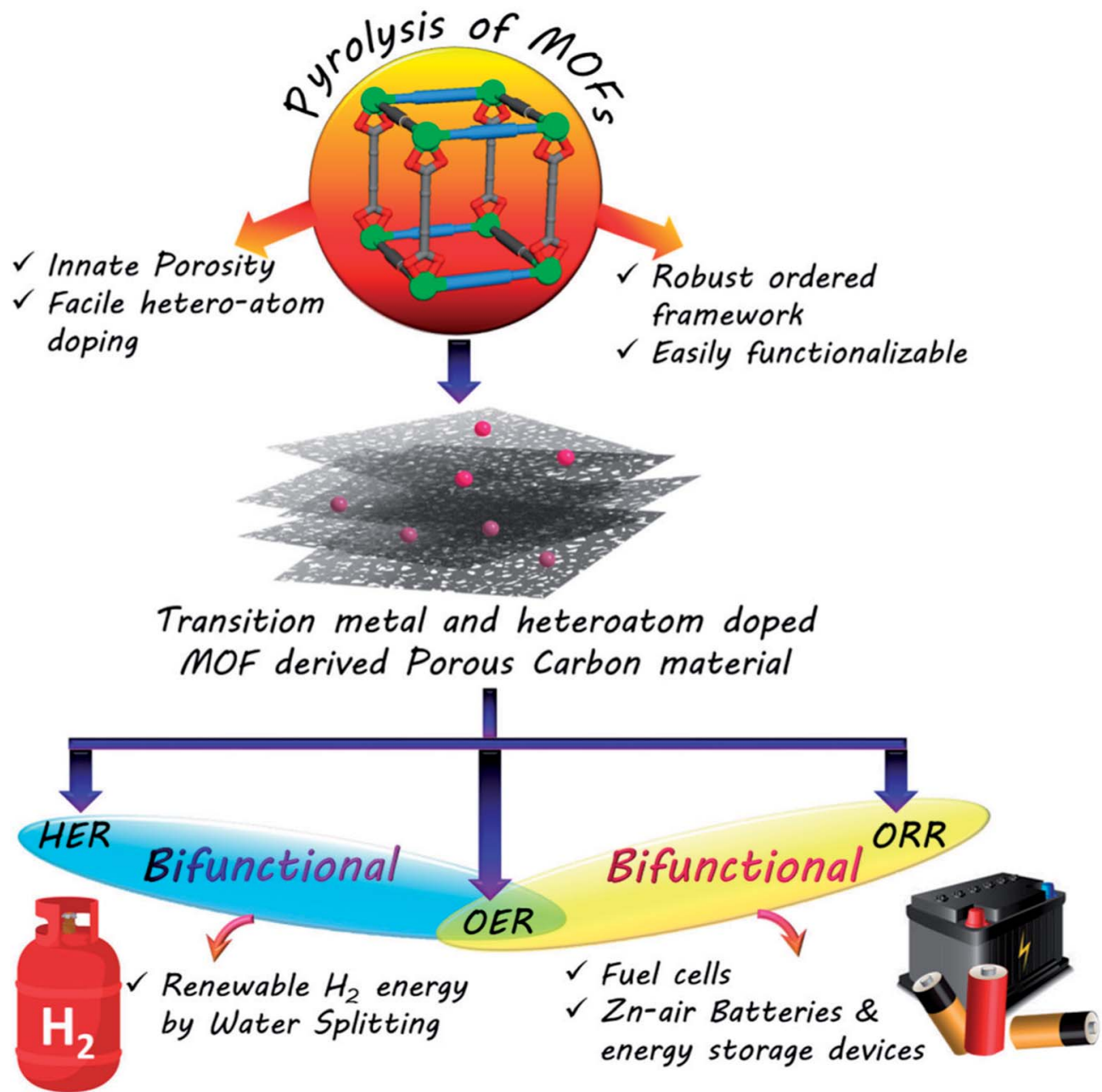

Scheme 1 Development of electrocatalysts from MOF derived carbon materials.

comfortably. By careful selection of metal and linkers and altering the stoichiometry, one can achieve structures that have supreme electrochemical activity. Frameworks containing earth abundant redox-active first row transition metals (e.g., Fe, Co, $\mathrm{Ni}, \mathrm{Mn}$, etc.) are particularly suitable for the job. Upon being coupled with a redox active linker, MOFs can show excellent electrochemical activity. ${ }^{168}$ Moreover the isolated metal nodes in MOFs enclosing nanoconfines are ideal for molecular catalysis. In spite of several advantages, the biggest drawback in using MOFs as electrocatalysts is their poor conductivity that limits the electrochemical activity. ${ }^{91}$ The most common way to counter this is to introduce catalytic nanoparticles or conductive guest species in the pores of the MOF, e.g., TCNQ or TTF. ${ }^{22}$ Sometimes the formation of composites with highly conductive materials like graphene is also advantageous. ${ }^{169} \mathrm{~A}$ composite of a $\mathrm{Zr}-\mathrm{MOF}$, NU-1000 with Ni-S films has shown excellent activity as a catalyst for HER. ${ }^{93}$ Growing MOFs as thin films is another strategy for generating productive electrocatalysts, as the control over film thickness is crucial to facilitate electron transport through the active catalytic sites. Yang et al. used thin films of $\mathrm{Co}^{-}$ porphyrin nanoMOF for the electrochemical reduction of $\mathrm{CO}_{2}{ }^{94}$ However, the most effective strategy to fabricate electrocatalysts from MOFs is the synthesis of MOF derived carbonaceous materials.

Porous carbon when doped with heteroatoms, e.g., $\mathrm{N}, \mathrm{S}$ or B, have been reported to show enhanced electrocatalytic activities, comparable to some of the noble metal-based benchmark catalysts. Also, non-precious metal and metal oxide nanoparticles (NPs) supported on carbon matrix (MNPC) with high porosity offer numerous exposed and easily accessible active sites, thereby improving overall electrocatalytic activity. ${ }^{67,68,70,75,95,96}$ However, the traditional methods for synthesis of such porous carbon materials involves simple pyrolysis followed by physical or chemical activation of organic precursors, which often gives rise to highly disordered structures with broad pore size distribution. This paved the way for nanocasting or templating approaches, initiated using soft templates, e.g., resols and hard templates, e.g., zeolites. ${ }^{97,98}$ These were again found to be unsuitable for bulk scale production. In an innovative approach, Xu et al. first proposed MOFs as self sacrificial templates for effective synthesis of porous carbon..$^{91}$ The inherent porosity of MOF, high surface area, large carbon content and ordered structure makes them ideal candidates as templates for carbon 
materials. They also ensure facile heteroatom and metal doping in the carbon matrix, thereby producing novel materials with enhanced properties. In many cases, precursors like furfuryl alcohol, sucrose, glycerol, phenolic resin, etc. are introduced in the MOF templates as a carbon source. However, it is also possible to make such materials without the use of any external precursor and the original MOF linker is treated as a source for carbon as well as heteroatoms like $\mathrm{N}$ or $\mathrm{S}$. Because of their electron rich surfaces, such heteroatom doped carbon materials have the potential to manifest excellent electrocatalytic activity. In addition, if the original electroactive metal atom of the MOF is retained in the form of metal or metal oxide nanoparticles, the electrochemical activity can be further enhanced.

To put it in layman's terms, electronic properties of a particular material dictates its efficiency as an electrocatalyst. ${ }^{99,100}$ A pure graphitic carbon matrix consisting of $\mathrm{sp}^{2}$ bonded carbon atoms with an uniformly delocalized electron cloud lacks polarization and consequently cannot afford to accommodate a foreign electronic cloud of intermediates. ${ }^{\mathbf{1 0 1}}$ Heteroatoms, e.g., N, B, P or S, with different electronegativities when introduced into this graphitic matrix, a redistribution of the electronic cloud takes place, thereby creating a polarization which can now accommodate the foreign invasion of intermediates. ${ }^{\mathbf{1 0 2 , 1 0 3}}$ The most commonly doped heteroatom is nitrogen which is more electronegative and hence these doping sites are potent for metal/functional group coordination and act as active sites for the electrocatalysis. ${ }^{\mathbf{9 9 , 1 0 0}}$ The heteroatom doped carbon matrix have the potential to act as efficient metal free electrocatalysts. ${ }^{\mathbf{1 0 4 - 1 1 1}}$ One of the primary reasons to choose MOFs as templates for carbonization is the ease of including heteroatoms in the carbon matrix, by simply selecting a MOF with a heteroatom containing linker. For example, MOFs with imidazolate framework are often pyrolyzed at inert atmosphere to get $\mathrm{N}$-doped carbon matrix with large surface area. ${ }^{\mathbf{1 1 2 - 1 1 9}}$ Muhler et al. showed the formation of core-shell $\mathrm{Co@} \mathrm{Co}_{3} \mathrm{O}_{4}$ nanoparticles embedded in carbon nanotubes (CNTs) by the direct carbonization of ZIF-67, a Co imidazolate framework ${ }^{\mathbf{1 2 0}}$ (Fig. 1(b)). Other N-containing linkers, e.g., pyridine derivatives may also be used. We showed the formation for Co doped carbon nanotubes (CoCNTs) by the pyrolysis of dicyanamide based nitrogen rich MOF $\left\{\left[\mathrm{Co}(\mathrm{bpe})_{2}\left(\mathrm{~N}(\mathrm{CN})_{2}\right)\right] \cdot\left(\mathrm{N}(\mathrm{CN})_{2}\right) \cdot\left(5 \mathrm{H}_{2} \mathrm{O}\right)\right\}_{n} \quad$ [Co-MOF-1, bpe $=1,2$-bis(4-pyridyl)ethane, $\mathrm{N}(\mathrm{CN})_{2}{ }^{-}=$dicyanamide.$^{121}$ However, in most cases, scientists opt for external N-sources like urea, melamine, etc. to generate $\mathrm{N}$ containing $\mathrm{C}$ materials. Kurungot et al. performed the pyrolysis MOF5 in the presence of nitrogen rich melamine to generate $\mathrm{g}-\mathrm{C}_{3} \mathrm{~N}_{4}$ for electrocatalytic ORR (Fig. 1(a)). ${ }^{122}$ Guest molecules impregnated within the MOF pores may also be used as a source of heteroatom. ${ }^{\mathbf{1 1 9 , 1 2 3 - 1 2 8}}$ In an interesting piece of work, we have utilized a guest dimethyl amine cation of an anionic MOF as a pre-bonded $\mathrm{C}-\mathrm{N}-\mathrm{C}$ moiety to generate $\mathrm{N}$-doped C-dots. ${ }^{129}$ Also, co-doping two or more elements with reverse electronegativity results in greater number of defects, generating more number of active sites for an elevated electrocatalytic activity. Thus, compared to single heteroatom doping, multiple heteroatom doping could be beneficial. For this, either the ligand must be selected such that it has the choice of heteroatoms or the MOF can be impregnated with heteroatom containing moieties.

It has already been established that metals/metal oxides and their nanoparticles (NPs) play an integral role in the electrocatalysis. ${ }^{\mathbf{4 6 , 5 0 , 5 2 , 5 9 , 1 3 0 , 1 3 1}}$ The more recent literature presents that metal/metal oxide NPs encapsulated inside carbon matrix are also effective in improving the electrocatalytic activity. ${ }^{54,67,95,132,133}$ MOFs, containing redox-active metal nodes and carbon rich organic ligands thus become the automatic choice of sacrificial templates for preparing metal NPs embedded in a carbon matrix. Introduction of more than one transition metal in the matrix has also been proven beneficial in enhancing the electrocatalytic activity. ${ }^{\mathbf{1 3 4 - 1 3 7}}$ Post-synthetic metal exchanged MOF, metal cores coated with MOF, bimetallic MOFs are some of the possible sacrificial precursor for the preparation of multiple transition metal electrocatalysts. ${ }^{134,135,138,139}$ Depending upon the carbonization atmosphere, encapsulations and type of post treatments, metal carbides, nitrides, oxides, sulphides or phosphides are formed. Shim et al. pyrolysed an 1D coordination polymer synthesized from $\mathrm{Zn}$ and dithiooxamide linker doped with hemoglobin to generate $\mathrm{Fe}, \mathrm{S}$ and $\mathrm{N}$ doped carbon matrix (FeSNC) which showed excellent activity as a supercapacitor and electrocatalyst for ORR (Fig. 1(c)). ${ }^{158}$

Morphology of the MOF or the derived material also plays a crucial role in determining its electrochemical activity. The porosity of the composite depicts the active site accessibility and consequently the efficacy. However, high temperature annealing sometimes causes the framework to shrink and lose porosity, surface area and active site accessibility. Although this may be addressed by controlling the annealing temperature, however there is no clear solution to counter it and thus morphology control still remains a challenge. An effective and desirable electrocatalyst should have highly accessible active catalytic sites, facile electron transfer all over the matrix in order to get good conductivity and usage of earth abundant transition metals to curtail cost. A cautious balance of these features is the key to generate effective electrocatalysts for sustained use. In summary, MOFs are one of the best suited templates for the generation of such porous carbon based matrices for electrochemical applications because of the following reasons:

(a) The nanocasting approach of using MOF templates is extremely effective because of the ordered structure and innate porosity. Thus MOFs ensure facile encapsulation of carbon or heteroatom containing guest species.

(b) The various nanoscale morphologies of MOFs ensure similar morphologies in their carbon counterparts, exposing active sites.

(c) MOFs can be efficiently grown over conductive surfaces or substrates as nanomorphologies or thin films, ensuring better activity.

In the following paragraphs, few electrocatalysts prepared using the above strategies are discussed categorically as ORR, OER, HER and bifunctional catalysts. 

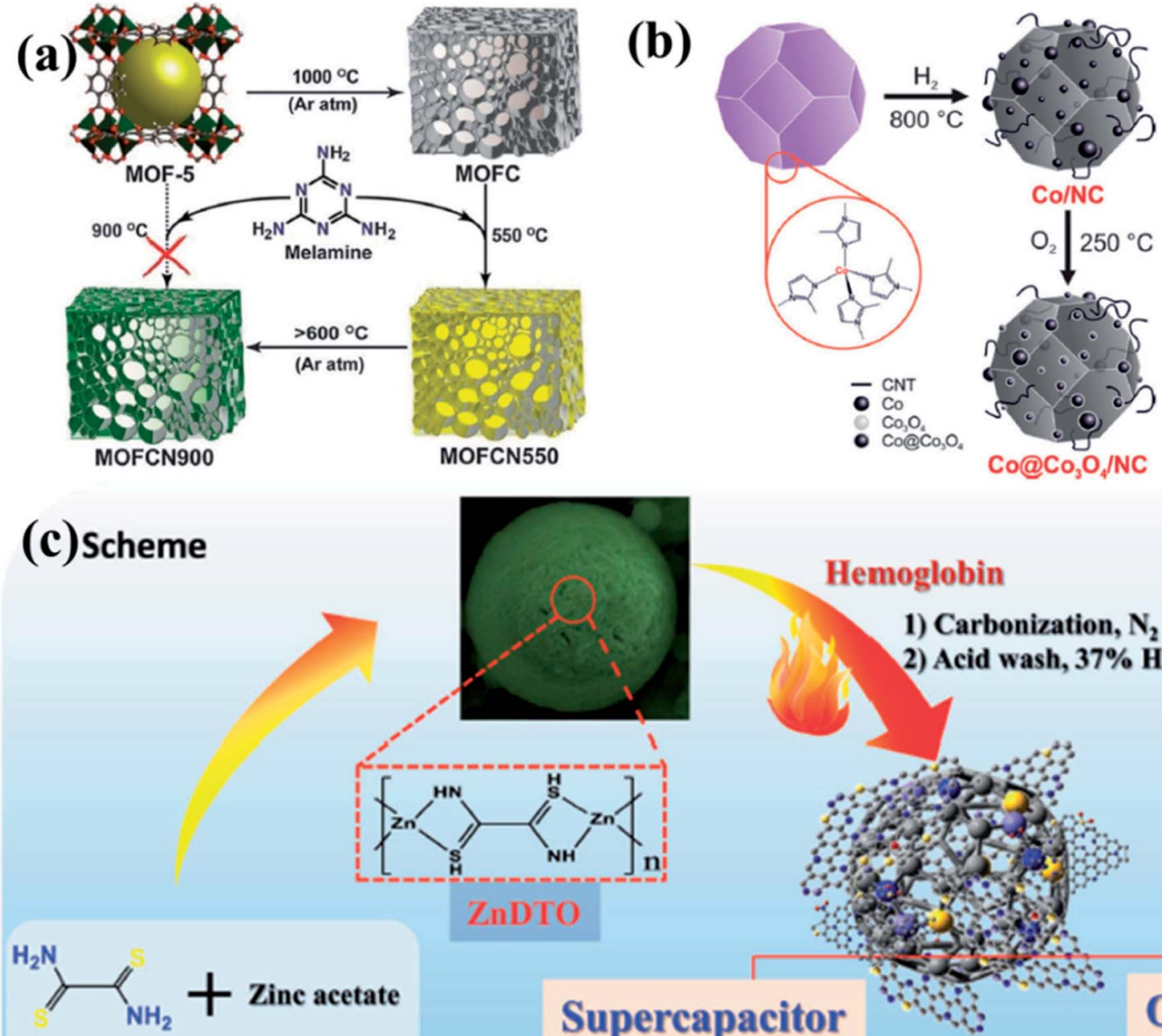

Dithioxamide (DTO)

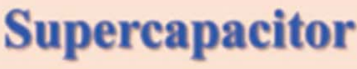

\section{Hemoglobin}

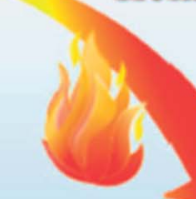

1) Carbonization, $\mathrm{N}_{2}$ 2) Acid wash, $37 \% \mathrm{HCl}$
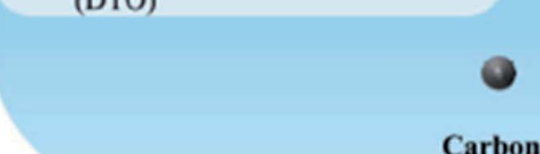

Carbon

Nitrogen Sulfur

Iron

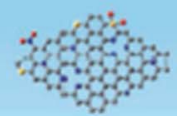

Graphene sheet

Fig. 1 (a) Schematic representation of generation of graphitic carbon nitride from MOF5 using melamine as a precursor. Reproduced with permission from ref. 122. Copyright 2014 American Chemical Society. (b) Synthesis of $\mathrm{Co}_{0} \mathrm{CO}_{3} \mathrm{O}_{4} / \mathrm{NC}$ from ZIF-67 by tuning the annealing temperature and atmosphere. Reproduced with permission from ref. 120. Copyright 2016 Wiley. (c) Doping of Fe, N and S in the carbon matrix using a 1D ZnDTO coordination polymer. Reproduced with permission from ref. 158. Copyright 2017 Wiley.

\section{MOF derived carbon nanocomposites in ORR, OER and HER}

\subsection{MOF derived materials for oxygen reduction reaction} (ORR)

Reduction of oxygen is not only one of the most important reactions in animal physiology, but also important industrially, particularly in fuel cells and metal-air batteries. In this process, oxygen may either gain two electrons to form $\mathrm{H}_{2} \mathrm{O}_{2}$ or four electrons to form $\mathrm{H}_{2} \mathrm{O}$. The kinetics of this reaction is extremely sluggish in nature and requires catalysts for its progress. Till date, the best known catalyst for this has been platinum, which because of its scarcity and immense expenses, has kept all attempts of commercializing ORR based technologies at bay. Thus over the past few decades, one of the major topics of research in materials science has been the incessant quest for cheaper, sustainable, environmentally benign catalyst for ORR. Some of the nanoporous carbons have shown tremendous potential as electrocatalysts for ORR. As mentioned previously, heteroatom doping plays an important role in creating defects in the carbon matrix which in turn reflects in the improvement of the catalytic activity.

The most common approach to prepare N-doped MOF derived electrocatalyst is to select a MOF with a N-rich ligand, viz., imidazole (IM), in particular the ZIF series of MOFs. You 
et al. showed that direct pyrolysis of ZIF-67 $\left(\mathrm{Co}(\mathrm{MIM})_{2}, \mathrm{MIM}=\right.$ methylimidazole) produced a highly $\mathrm{N}$-doped carbonaceous material with Co impregnation. ${ }^{156}$ Metal free, $\mathrm{N}$-doped porous carbon material was prepared by Cao and group where they treated ZIF-7 $\left(\mathrm{Zn}(\mathrm{PhIM})_{2} \cdot\left(\mathrm{H}_{2} \mathrm{O}\right)_{3}\right.$; PhIM = benzimidazole $)$ with glucose as an external excess carbon source. ${ }^{\mathbf{1 4 0}}$ The carbonized material was tested as an electrocatalyst for ORR and it showed an onset potential of $0.7 \mathrm{~V} v$ s. RHE, selective $\mathrm{H}_{2} \mathrm{O}$ production without any methanol crossover effect.

A series of bimetallic ZIFs (BMZIFs) with varied $\mathrm{Zn} /$ Co ratio were also studied for preparation of porous carbon materials where $\mathrm{N}$ was doped uniformly by Jiang and group (Fig. 2(a)). ${ }^{141} \mathrm{Zn}$ got evaporated leaving Co decorated N-doped carbon matrix (CNCo- $n$ ) ( $n$ indicating the $\mathrm{Zn} / \mathrm{Co}$ molar ratio in the precursor BMZIF). Later CNCo- $n$ was doped with $\mathrm{P}$ by annealing it with triphenylphosphine under $\mathrm{N}_{2}$ atmosphere (Fig. 2(b-d)). CNCo-20 when studied as an ORR electrocatalyst showed an onset potential of -0.08 vs. $\mathrm{Ag} / \mathrm{AgCl}$, on P-doping $(\mathrm{P}-\mathrm{CNCo}-20)$ the onset potential shifted towards more positive potential $(-0.04 \mathrm{~V} v s . \mathrm{Ag} /$ AgCl) (Fig. 2(e-g)). These catalysts also showed long term stability and good methanol tolerance. Tang and co-workers postsynthetically treated a Co-MOF (ZIF-67) with $\mathrm{NiCl}_{2}$ solution to get $\mathrm{Ni} / \mathrm{Co}-\mathrm{MOF}$ which on pyrolysis transformed into a highly porous carbon matrix with uniformly distributed Co, Ni and $\mathrm{N}$ centres, ensuring a high density of active sites with superior ORR activity in electrolytic solution of neutral to higher $\mathrm{pH} .{ }^{\mathbf{1 4 2}}$

Carbonization of self-adjusted $\mathrm{Zn}$ and Co bimetal-organic frameworks (bi-MOF) $\left[\mathrm{Zn}_{x} \mathrm{Co}_{1-x}(\mathrm{MeIM})_{2} ; \mathrm{MeIM}=\right.$ methyl imidazole] resulted in $\mathrm{Co}-\mathrm{N}-\mathrm{C}-x$ composites. Among these materials, $\mathrm{Co}-\mathrm{N}-\mathrm{C}-0.8$ was found to be the most active toward the ORR due to the presence of pyridinic $\mathrm{N}(47 \%)$, pyrrolic $\mathrm{N}$ $(43 \%)$, and oxidized $\mathrm{N}(10 \%)$ in the carbon matrix. ${ }^{143}$

In an attempt to understand the effect of annealing temperature on the morphology of MOF derived materials, recently our group documented synthesis of nanoporous carbon and nitrogen doped carbon dots from $\mathrm{Mg}(\mathrm{II})$ based anionic MOF (Mg-MOF) $\left\{\left[\mathrm{Mg}_{3}(\mathrm{ndc})_{2.5}\left(\mathrm{HCO}_{2}\right)_{2}\left(\mathrm{H}_{2} \mathrm{O}\right)\right] \cdot\left[\mathrm{NH}_{2} \mathrm{Me}_{2}\right] \cdot\right.$ $\left.2 \mathrm{H}_{2} \mathrm{O} \cdot \mathrm{DMF}\right\}$ (ndc = naphthalene dicarboxylate) by varying the carbonizing temperature. ${ }^{129}$ The nanoporous carbon (NPC) obtained by carbonizing $\mathrm{Mg}-\mathrm{MOF}$ at $900{ }^{\circ} \mathrm{C}$ and subsequently washing with a concentrated acid mixture $\left(\mathrm{HCl}: \mathrm{HNO}_{3}\right.$ in $1: 1$ $\mathrm{v} / \mathrm{v}$ ). N-doped carbon dots (NCD) were obtained at $500{ }^{\circ} \mathrm{C}$ by treating in similar conditions (Fig. 3(a)). Both NPC and NCD were characterized by IR, Raman, XPS, XRD and several microscopic techniques. NPC showed BET surface area of 3690 $\mathrm{m}^{2} \mathrm{~g}^{-1}$, which is one of the highest surface areas of a porous

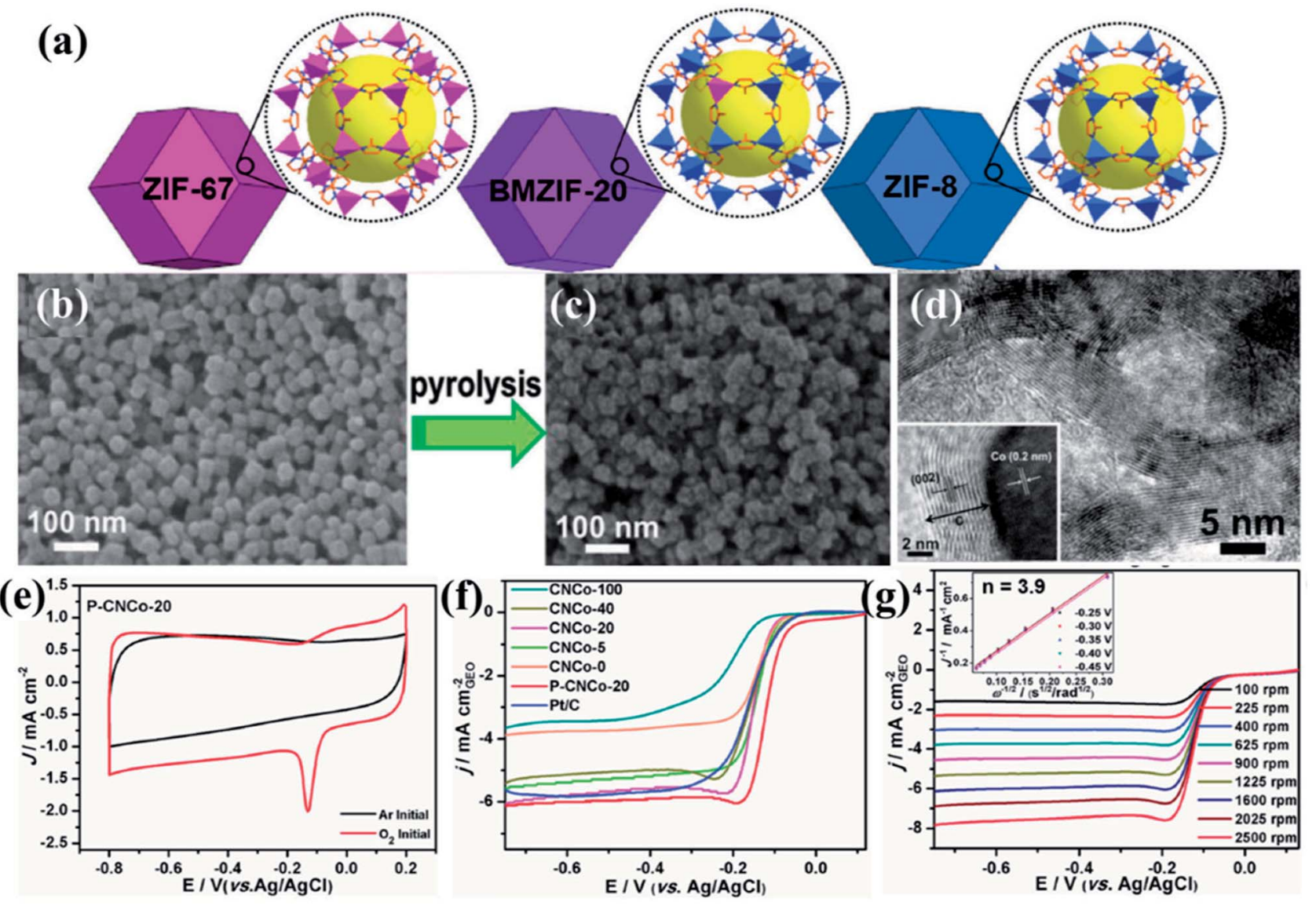

Fig. 2 (a) Schematic representation of the imidazole based frameworks used for carbonization. SEM images of (b) BMZIF-20 and its pyrolysed counterpart (c) CNCo-20. (d) TEM image showing Co nanoparticles embedded in layers of graphitized carbon. (e) CV of P-CNCo-20 in 0.1 M $\mathrm{KOH}$ in $\mathrm{Ar}$ and $\mathrm{O}_{2}$ saturated conditions. (f) LSV curves for the different carbonized samples in $0.1 \mathrm{M} \mathrm{KOH}$ at $1600 \mathrm{rpm}$. (g) LSV curves at different rotation speeds for P-CNCo-20 in 0.1 M KOH. Reproduced with permission from ref. 141. Copyright 2015 Wiley. 
(a)

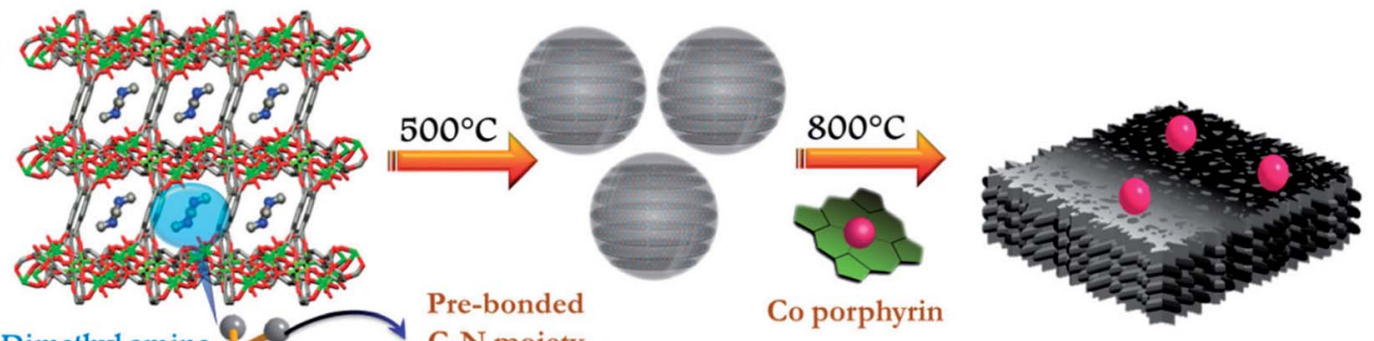

Dimethyl amine $\left(\mathrm{NH}_{2} \mathrm{Me}_{2}{ }^{+}\right)$Cations
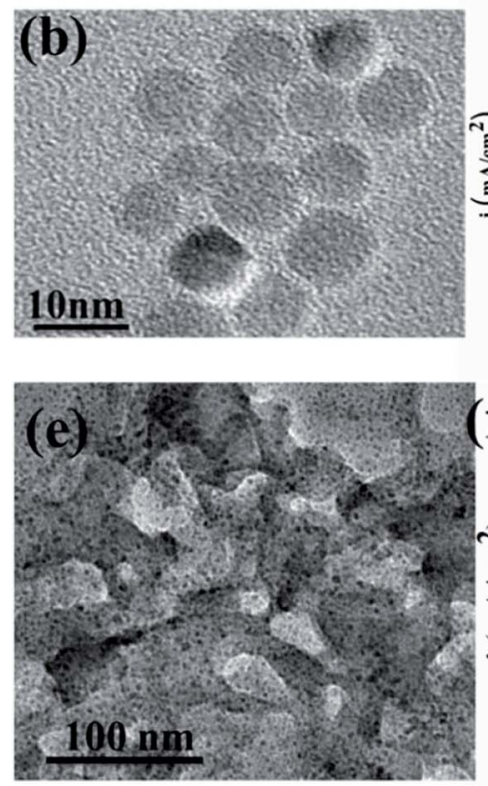

C-N moiety
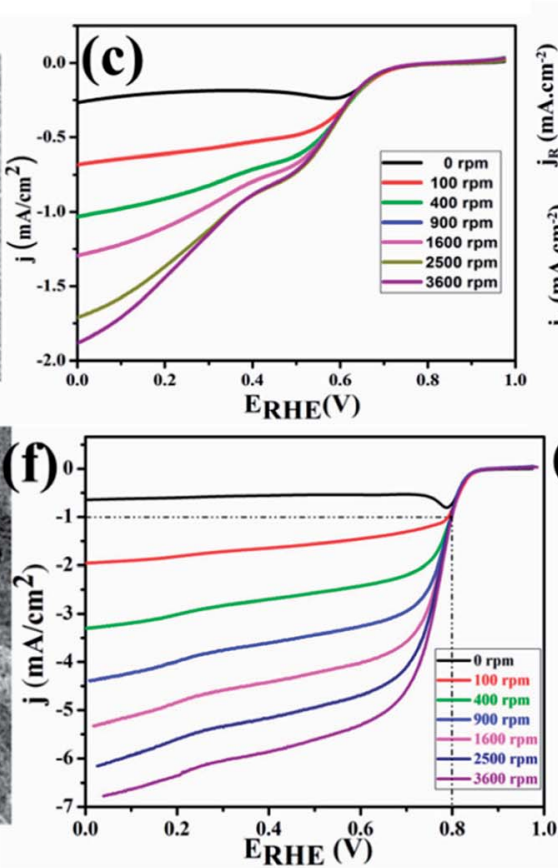
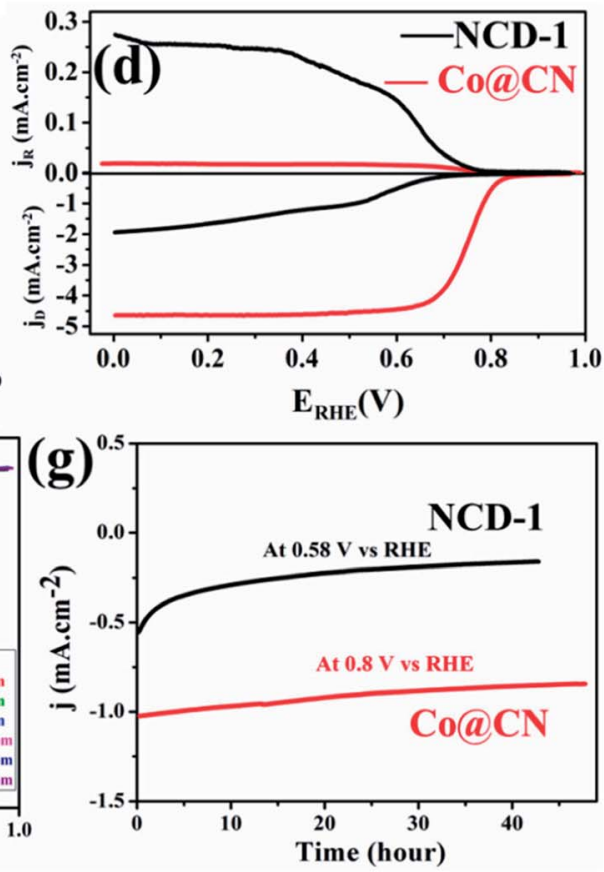

Fig. 3 (a) Schematic representation of the pyrolysis of 1 at $500^{\circ} \mathrm{C}$ to generate $\mathrm{N}$-doped $\mathrm{C}$-dots and further Co doping in it. (b) TEM image of the $\mathrm{N}$-doped C-dots formed by carbonizing 1. (c) LSV curves for ORR by NCD-1. (d) RRDE voltammograms collected at $5 \mathrm{mV} \mathrm{s}{ }^{-1}$ and 1600 rpm showing ORR in $0.1 \mathrm{M} \mathrm{KOH}$. (e) TEM image of CoaCN. (f) LSV curve for ORR in $0.1 \mathrm{M} \mathrm{KOH}$ for Co@CN. (g) Chronoamperometric response for NCD-1 and Co@CN. Reproduced from ref. 129. Copyright 2017 Royal Society of Chemistry.

carbon obtained from directly carbonizing a MOF. The presence of DMA $\left(\mathrm{NH}_{2} \mathrm{Me}_{2}\right)$ containing prebonded $\mathrm{C}-\mathrm{N}$ moieties in the pore of the anionic Mg-MOF helped in the synthesis of $\mathrm{N}$-doped carbon dots. The diameter of each dot is well below $10 \mathrm{~nm}$ and HRTEM showed graphitic lattice fringes with an inter planar distance of $0.34 \mathrm{~nm}$ (Fig. 3(b)). Surface area of NCD is about 95 $\mathrm{m}^{2} \mathrm{~g}^{-1}$. NCD has structural and compositional features similar to $\mathrm{g}^{-} \mathrm{C}_{3} \mathrm{~N}_{4}$ which is known to show good catalytic activity for ORR. Linear sweep voltammetry (LSV) at different rotation speeds was performed and NCD showed moderate catalytic activity for ORR (Fig. 3(c)). To further improve the catalytic activity, Co atoms were doped in the NCD. This was achieved by mixing Co-porphyrin with NCD and the mixture was pyrolized at $800{ }^{\circ} \mathrm{C}$ and a new composite was obtained. PXRD, XPS and TEM analysis suggest the presence of metallic Co-nanoparticle on the N-doped graphitic carbon (Fig. 3(e)). XRD also suggested the tris-s-triazine units in carbon nitride, remain intact after Co-doping. TEM study showed that metallic Conanoparticles (less than $5 \mathrm{~nm}$ ) embedded in a carbon matrix and lattice spacing of $0.24 \mathrm{~nm}$ corresponded to fcc Co. ICP analysis suggested about $1.5 \mathrm{wt} \%$ of Co in the Co@CN nanocomposite material. ORR activity was studied using Co@CN sample and a significant difference was observed with respect to NCD. LSV of Co@CN showed significantly enhanced cathodic current as a function of rotation speed and affording a current density of $-1 \mathrm{~mA} \mathrm{~cm} \mathrm{~cm}^{-2}$ at low overpotentials $(\sim 0.8 \mathrm{~V})$ as compared to $0.36 \mathrm{~V}$ for NCD (Fig. 3(f)). K-L plot revealed that linearity and the number of electrons transferred during the ORR is 3.87 , suggesting 4 electron transfer pathway to produce $\mathrm{H}_{2} \mathrm{O}$ after $\mathrm{O}_{2}$ reduction. Further, rotating ring disk electrode (RRDE) measurement showed that $\mathrm{H}_{2} \mathrm{O}_{2}$ production is decreased from $40.8 \%$ for NCD to $2.3 \%$ for Co@CN (Fig. 3(d)). The Tafel slopes for Co@CN were $63 \mathrm{mV}$ per decade and $141 \mathrm{mV}$ per decade at lower and higher current density respectively, suggesting faster reaction kinetics. Chronopotentiometric (CP) electrolysis study were performed for both NCD and Co@CN at a constant voltage for $48 \mathrm{~h}$ at a rotation speed of $1600 \mathrm{rpm}$ (Fig. 3(g)). Both the catalysts showed excellent stability in alkaline solution during ORR. Overall, these results demonstrated that NCD catalyze the reduction of $\mathrm{O}_{2}$ to $\mathrm{H}_{2} \mathrm{O}_{2}$ and 
metallic Co-nanoparticles catalyze the decomposition of the formed $\mathrm{H}_{2} \mathrm{O}_{2}$. Such enhanced catalytic activity in Co@CN can be attributed to the electronic interaction between the metal nanoparticles and graphitic carbon, which accelerates the kinetics of the ORR.

A similar attempt by Liang et al., yielded $\mathrm{N}$ and $\mathrm{S}$ doped mesoporous carbon by annealing an inherently $\mathrm{N}$ and $\mathrm{S}$ containing MOF $\left[\mathrm{Zn}_{2}(\mathrm{TDC})_{2}(\mathrm{DABCO})\right] \cdot 4 \mathrm{DMF}$ (SCUT-12, TDC $=2,5$ thiophenedicarboxylic acid, DABCO $=1,4$-diazabicyclo[2.2.2] octane) without the use of any external dopant. Owing to different pyrolysis temperatures, the S content and type varied, giving different ORR activities. Overall the material showed excellent ORR activity comparable to Pt/C catalyst. ${ }^{\mathbf{1 4 4}}$

Zou and co-workers studied the effect of particle size of nano MOF and the corresponding derived material on the catalytic activity. ${ }^{\mathbf{1 4 5}}$ They synthesized ZIF-67 (Fig. 4(a)) in various conditions to achieve different particle sizes ranging from bulk to $300 \mathrm{~nm}$. The polyhedral morphology of the MOF nanoparticles were retained in the MOF derived carbon materials (MDCs) by carefully choosing the pyrolyzing temperature under Ar atmosphere, which is ascertained from TEM and SEM studies (Fig. 4(b and c)). TEM also proves the presence of Co in the carbon matrix (Fig. 4(c)). The effect of size of the particles directly affects the electrocatalytic activity, as observed by recording the LSV curves for the different samples (Fig. 4(d)). The LSV shows a lesser overpotential for onset of ORR $(0.86 \mathrm{~V} v s$. RHE) for the lowest size MDC (300 nm) than for the MDC derived from bulk MOF ( $0.80 \mathrm{~V} v s$. RHE). The electron transfer pathway was also affected by the particle size, as the $300 \mathrm{~nm}$ MDC shows 4-electron transfer with the highest stability (Fig. 4(e)). This study establishes that with smaller particle size, the active sites are much more exposed and easily accessible which promotes faster mass and electron transfer.

The effect of morphology on electrochemical activity was presented in an intriguing work by Yu et al. ${ }^{\mathbf{1 4 6}}$ where tellurium nanowires (TeNWs) were used as templates for growing ZIF-8 nanofibers (Fig. 5(a and b)). Carbonization of the resultant high aspect ratio ZIF-8 nanofibers at $1000{ }^{\circ} \mathrm{C}$ yields highly porous $\mathrm{N}$-doped carbon nanofibers (Z8-Te-1000) which retain the hollow fibrous morphology with uniform diameter of $50 \mathrm{~nm}$ (Fig. 5(c)). The electrocatalytic activity of Z8-Te-1000 was primarily shown in the CVs recorded in $\mathrm{O}_{2}$ and $\mathrm{N}_{2}$ saturated $0.1 \mathrm{M} \mathrm{KOH}$ solution separately (Fig. 5(d)). The Z8-Te-1000 showed good catalytic activity towards ORR which is apparent from the LSVs recorded at different rotation speeds and the corresponding $\mathrm{K}-\mathrm{L}$ plot (Fig. 5(e,f)). To further increase the catalytic activity reannealing with triphenylphosphine was done which resulted in P-doping (P-Z8-Te-1000). P-Z8-Te-1000 shows excellent activity as an electrocatalyst for ORR, even superior to the benchmark Pt/C catalyst (Fig. 5(g)). However, the carbon material obtained by the direct pyrolysis of bulk ZIF-8 does not show good electrocatalytic activity (Fig. 5(g)).

A remarkable piece of work by Yu et al., utilizes the bifunctionality observed in a MOF-derived porous carbon for direct use in $\mathrm{Zn}$-Air and $\mathrm{Li}-\mathrm{S}$ batteries. In this case, a dual templating approach was followed where initially an ordered silica photonic crystal template was produced from $200 \mathrm{~nm}$ silica particles, followed by the infiltration by ZIF-8 precursor solution (Fig. 6(a)). Complete solvent evaporation yields uniform ZIF-8 crystals on the silica microsphere surface and in the interstitial voids (Fig. 6(b)). Next pyrolysis at high temperature of (800$1100{ }^{\circ} \mathrm{C}$ ) converted the composite into carbon morphologies supported on a silica matrix (Fig. 6(c)). A macroporous carbon texture with interconnected narrow walls between the special voids was obtained upon removing the silica matrix (Fig. 6(d)). The sample carbonized at $950{ }^{\circ} \mathrm{C}$ (BHPC-950) has a high total pore volume of $13.42 \mathrm{~cm}^{3} \mathrm{~g}^{-1}$, large specific surface area of 2546 $\mathrm{m}^{2} \mathrm{~g}^{-1}$ and a high nitrogen dopant content of 7.6 atom\%. BHPC-950 shows an excellent ORR activity with an onset potential of $0.93 \mathrm{~V}$ and a limiting current density of $5.34 \mathrm{~mA}$ $\mathrm{cm}^{-2}$ and a 4-electron pathway (Fig. 6(e)). Not only does it surpass the benchmark Pt/C catalyst in its activity, but also it shows a very small Tafel slope of $74 \mathrm{mV} \mathrm{dec}^{-1}$, signifying a large number of exposed active sites and swift ORR kinetics. However, a sample prepared by the direct carbonization of ZIF-8 nanocrystals under the same conditions without macropores does not show appreciable ORR activity. Since both the samples have equivalent $\mathrm{N}$ content, the reduced activity can only be attributed to the low specific surface area, due to the lack of macropores, less number of exposed sites and high masstransfer barrier. BHPC-950 was assembled by loading on carbon cloth as an air cathode along with a $\mathrm{Zn}$-foil as the anode in a Zn-air battery. BHPC-950 shows a high discharge current density of $319 \mathrm{~mA} \mathrm{~cm}^{-2}$ and peak power density of $197 \mathrm{~mW}$ $\mathrm{cm}^{-2}$ at catalyst loading of merely $0.5 \mathrm{mg} \mathrm{cm}^{-2}$ (Fig. 6(f)). The BHPC-950 battery shows a specific capacity of $797 \mathrm{~mA} \mathrm{~h} \mathrm{gzn}^{-1}$ corresponding to an energy density of $963 \mathrm{~W} \mathrm{~h} \mathrm{~kg}_{\mathrm{Zn}}{ }^{-1}$ at $20 \mathrm{~mA}$ $\mathrm{cm}^{-2}$, which corresponds to $95 \%$ utilization of theoretical capacity. The outstanding stability of BHPC-950 electrode is exhibited by the continuous lighting of a LED pattern comprising $302.2 \mathrm{~V}$ LED bulbs by two such $\mathrm{Zn}$-air batteries in series for more than $12 \mathrm{~h}$ without brightness decay (Fig. $6(\mathrm{~g})) \cdot{ }^{\mathbf{1 4 7}}$

Several other simplistic approaches have been undertaken to synthesize economically viable electrocatalysts for ORR with supreme activity. In fact, among the three electrochemical reactions mentioned here, the most number of MOF-derived electrocatalysts have been developed for ORR, upholding a new vista of possibilities.

\subsection{MOF derived electrocatalysts for oxygen evolution reaction (OER)}

Electrochemical water splitting has been highly regarded as one of the most important reactions in modern times in order to generate $\mathrm{H}_{2}$ for storing energy in the form of chemical bonds. One half of the water splitting reaction involves the evolution of oxygen from water also regarded as oxygen evolution reaction (OER). The reaction involved is as follows:

$$
\mathrm{H}_{2} \mathrm{O}+2\left(\mathrm{~h}^{+}\right) \rightarrow \frac{1}{2} \mathrm{O}_{2}+2 \mathrm{H}^{+}
$$

The efficiency of this reaction is not only essential for the overall water splitting reaction, but this is also an important 


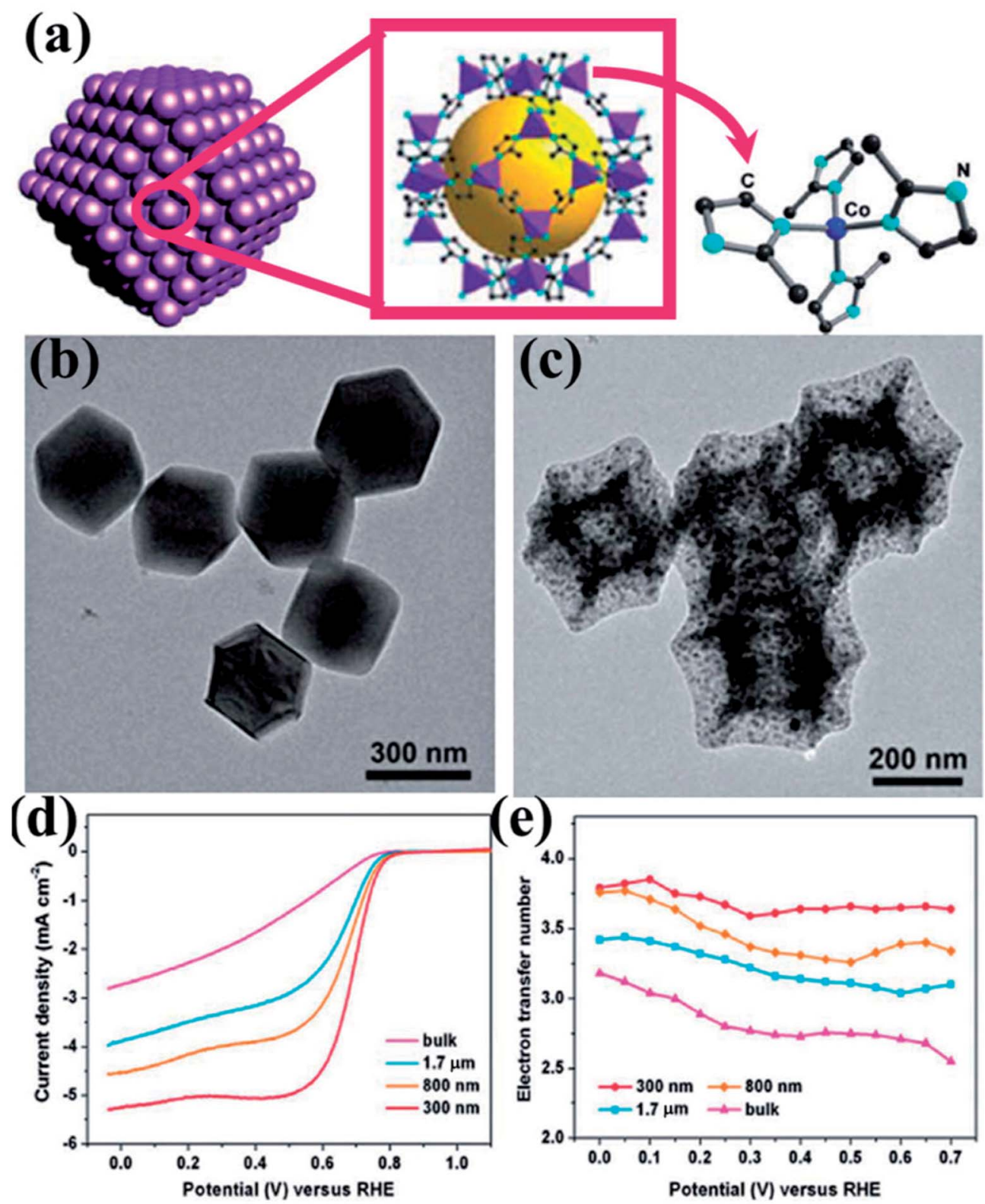

Fig. 4 (a) Schematic representation of ZIF-67 nanopolyhedrons. (b) Polyhedral morphology of the ZIF-67 as seen under TEM. (c) TEM image showing preservation of polyhedral morphology after annealing at $750{ }^{\circ} \mathrm{C}$. (d) RDE polarization curves of $300 \mathrm{~nm}, 800 \mathrm{~nm}, 1.7 \mathrm{~mm}$ and bulk MDCs in $0.1 \mathrm{M} \mathrm{HClO}_{4}$ at a rotation rate of $1600 \mathrm{rpm}$; (e) the electron transfer number as a function of potential for MDCs with various sizes. Reproduced with permission from ref. 145. Copyright 2014 Royal Society of Chemistry.

anode reaction in fuel cells and metal-air batteries. However, similar to ORR, OER is also extensively dependent on expensive noble metal based catalysts, e.g., $\mathrm{IrO}_{2}$ or $\mathrm{RuO}_{2}$. Hence for the overall development of electrochemical technologies, it is important to develop cheaper alternatives for catalysis of OER.

In an interesting work, Lee and group used a layered Co-MoMOF (Fig. 7(a) $)^{159}$ as a template along with polyvinylpyrrolidone (PVP) as a structure directing agent as well as a $\mathrm{N}$ source for generating $\mathrm{N}$-doped carbon matrix. ${ }^{148} \mathrm{Here}$, the PVP is expected to lower the surface energy of the ultrathin Co-Mo-MOF layers and contribute in the formation of integrated 2D and 3D structures. Field effect scanning electron microscopic (FESEM) images show formation of hierarchical microstructure composed of the hybrid MOF (Co-Mo-MOF) nanowires (Fig. 7(b)). On pyrolyzing Co-Mo-MOF at $600^{\circ} \mathrm{C}, \mathrm{CoO}_{x}-\mathrm{MoC} / \mathrm{NC}$ were formed in the form of $3 \mathrm{D}$ nanowire assemblies, similar to the template. The FESEM images of the pyrolyzed material shows 3D micro-ribbon structures with evenly distributed metal nanoparticles (Fig. 7(c and d)). To realize an optimum Co/Mo ratio, MOFs with varied $\mathrm{Co} / \mathrm{Mo}$ ratio viz. $35.8: 1,21: 1$, $10.3: 1$ was prepared and the corresponding pyrolized products formed are $\mathrm{CoO}_{x}-\mathrm{MoC} / \mathrm{NC}-1, \mathrm{CoO}_{x}-\mathrm{MoC} / \mathrm{NC}-2$ and $\mathrm{CoO}_{x}-\mathrm{MoC} /$ $\mathrm{NC}-3$, respectively. The LSV of all the $\mathrm{CoO}_{x}-\mathrm{MoC} / \mathrm{NC}$ reveals an optimum electrocatalytic activity of $\mathrm{CoO}_{x}-\mathrm{MoC} / \mathrm{NC}-1$ with 
(a)

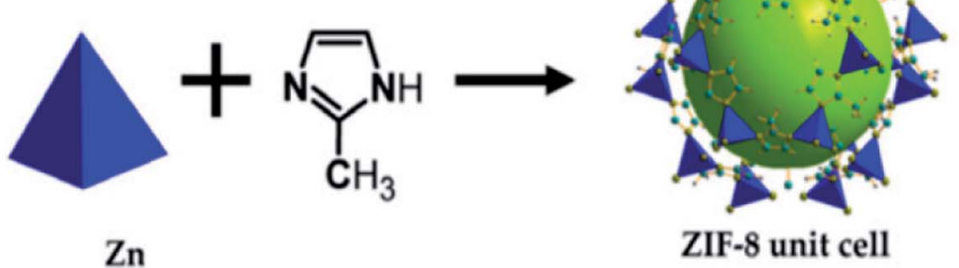

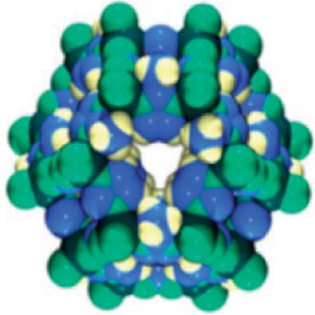

Space filling ZIF-8 pore
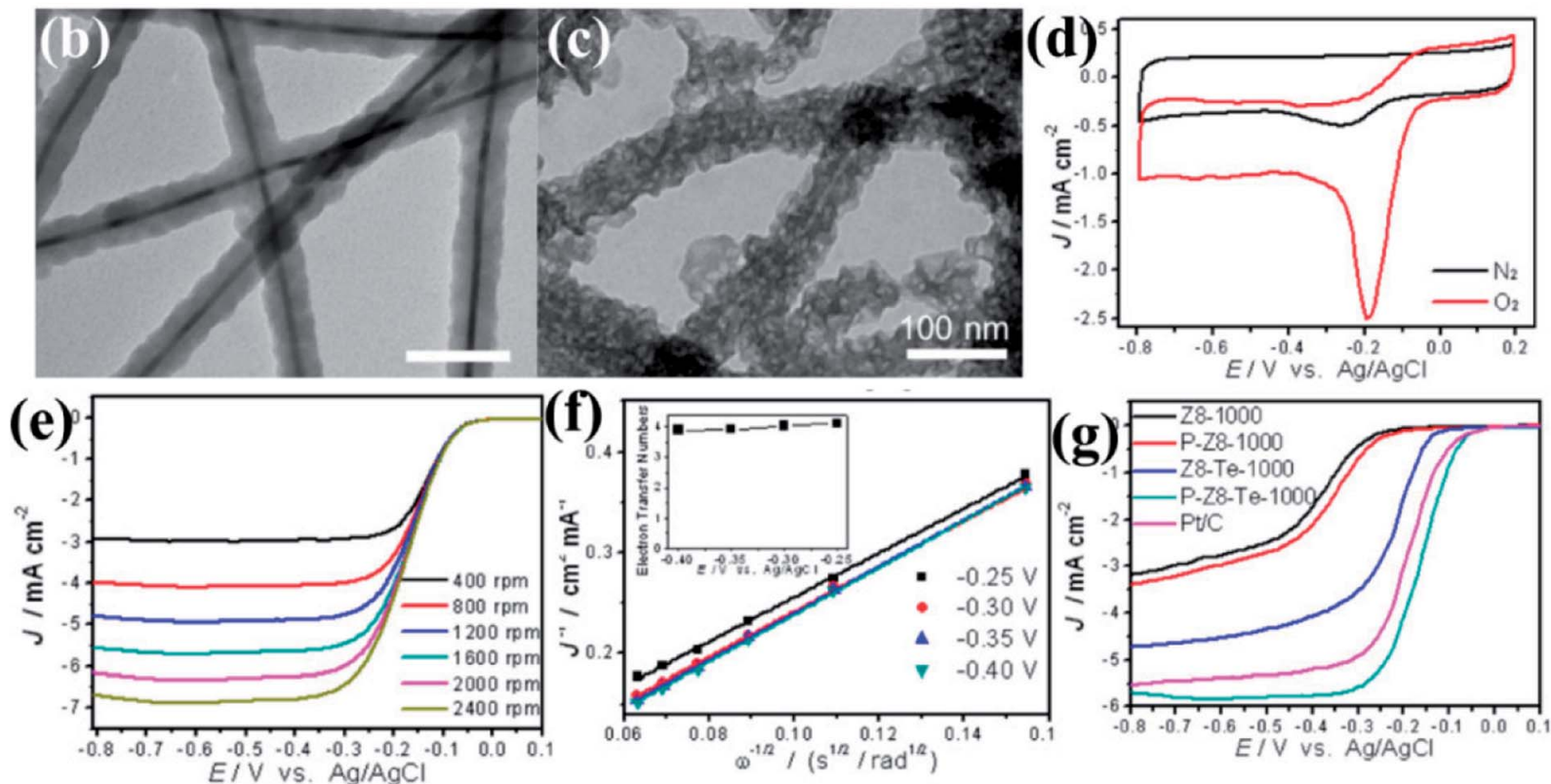

Fig. 5 (a) Representation of ZIF-8 unit cell and space filling pore of ZIF-8. Reproduced from ref. 161. TEM images of (b) Te@ZIF-8 with average diameter of $45 \mathrm{~nm}$ (c) Z8-Te-1000 showing hollow fibrous morphology. (d) CVs of P-Z8-Te-1000 in $\mathrm{O}_{2}$ and $\mathrm{N}_{2}$ saturated $0.1 \mathrm{M} \mathrm{KOH}$; (e) LSVs of P-Z8-Te-1000 recorded at different rotation rates and at a scan rate of $10 \mathrm{mV} \mathrm{s}^{-1}$; (f) Koutecky-Levich plots of P-Z8-Te-1000 derived from LVSs at different rotation speed; (g) LSVs of all the catalysts in $\mathrm{O}_{2}$ saturated $0.1 \mathrm{M} \mathrm{KOH}$ with a sweep rate of $10 \mathrm{mV} \mathrm{s}^{-1}$ and electrode rotation speed of 1600 rpm. Reproduced with permission from ref. 146. Copyright 2014 American Chemical Society.

lowest onset potential of $1.52 \mathrm{~V} v s$. RHE and lowest Tafel slope of $89.8 \mathrm{mV}$ per decade (Fig. 7(e and f)). It is evident from this that while a high $\mathrm{Co} / \mathrm{Mo}$ ratio does not ensure a high conductivity, a lower $\mathrm{Co} / \mathrm{Mo}$ ratio does not allow enough active sites for an enhanced catalytic activity. Hence, it is essential to have an optimum bimetallic ratio for efficient electrocatalysis of OER. The high catalytic activity of $\mathrm{CoO}_{x}-\mathrm{MoC} / \mathrm{NC}-2$ than the other $\mathrm{CoO}_{x}-\mathrm{MoC} / \mathrm{NCs}$ was probably due to higher specific surface area, which was confirmed by calculating electrochemical surface areas (ECSAs) from the double-layer capacitance. This was found to be highest for $\mathrm{CoO}_{x}-\mathrm{MoC} / \mathrm{NC}-2$, which also showed a very high stability.

$\mathrm{Li}$ and group effectively utilized a nickel foam to grow MOF and proceeded on to carbonize it. ${ }^{149}$ First, they electrodeposited polyaniline (PAni) on nickel foam (NF) (NF@PAni). The layer of PAni promptly traps transition metal ions and upon exposure to $\mathrm{H}_{2}$ dodc (2,5-dioxido-1,4-benzenedicarboxylic acid), the MOF-74$\mathrm{M}\left[\mathrm{M}_{2}\right.$ (dobdc) $]\left(\mathrm{M}=\mathrm{Fe}, \mathrm{Co}, \mathrm{H}_{2}\right.$ dodc $=$ 2,5-dioxido-1,4benzenedicarboxylic acid) grows on NF@PAni (NF@PAni@Co/ $\mathrm{Fe}_{2} \mathrm{O}_{4}$-NRAs). This layered substrate was eventually pyrolyzed at
$600{ }^{\circ} \mathrm{C}$ (Fig. 8). MOF-74-M was selected for the choice of metal ( $\mathrm{Fe}, \mathrm{Co}$ ) and a high $\mathrm{O} / \mathrm{C}$ ratio of the ligand. SEM images reveal the growth of MOF-74-Co/Fe nanorods (diameter $\sim 680 \mathrm{~nm}$ ) array (NRA) on NF@PAni (Fig. 9(a)). The subsequent heat treatment under $\mathrm{N}_{2}$ atmosphere yielded $\mathrm{Co} / \mathrm{Fe}_{2} \mathrm{O}_{4}-\mathrm{C}$, denoted as NF@NC@Co/ $\mathrm{Fe}_{2} \mathrm{O}_{4}-\mathrm{C}$ NRAs. Fig. 9(b) shows the SEM image of $\mathrm{Co} / \mathrm{Fe}_{2} \mathrm{O}_{4}-\mathrm{C}$ NRAs with the inset showing a magnified nanorod. The TEM images of $\mathrm{Co} / \mathrm{Fe}_{2} \mathrm{O}_{4}-\mathrm{C}$ ascertains the impregnation of metal NPs on a porous carbon matrix advantageous for catalytic activity (Fig. 9(c and d)).

Four types of electrodes were fabricated to show the advantages gained by growing NRAs on NF@PAni, which are as follows: (i) $\mathrm{CoFe}_{2} \mathrm{O}_{4}$ on $\mathrm{NF} @ \mathrm{NC}$ ( $\mathrm{NF} @ \mathrm{NC}-\mathrm{CoFe}_{2} \mathrm{O}_{4}$ ), (ii) $\mathrm{CoFe}_{2} \mathrm{O}_{4} / \mathrm{C}$ on NF@NC(NF@NC-CoFe $\mathrm{O}_{4} / \mathrm{C}$ ), (iii) commercial $\mathrm{IrO}_{2}$ on NF@NC (NF@NC-IrO $\mathrm{I}_{2}$ on NF@NC, (iv) NF@NC@C $\mathrm{CoFe}_{2} \mathrm{O}_{4} / \mathrm{C}$ NRAs. Upon performing the LSV, true to the conjecture of the authors, NF@NC@ $\mathrm{CoFe}_{2} \mathrm{O}_{4} / \mathrm{C}$ NRAs showed the lowest onset potential ( 1.45 vs. RHE) (Fig. 9(e)) and Tafel slope was found to be $\approx 45 \mathrm{mV} \mathrm{dec}^{-1}$ (Fig. 9(f)), indicative of an extremely fast kinetics. The nanorod 
(a)

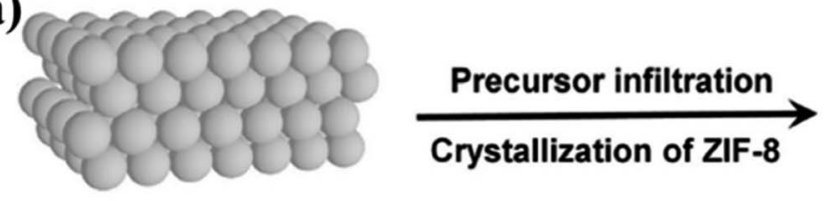

3D ordered $\mathrm{SiO}_{2}$ template
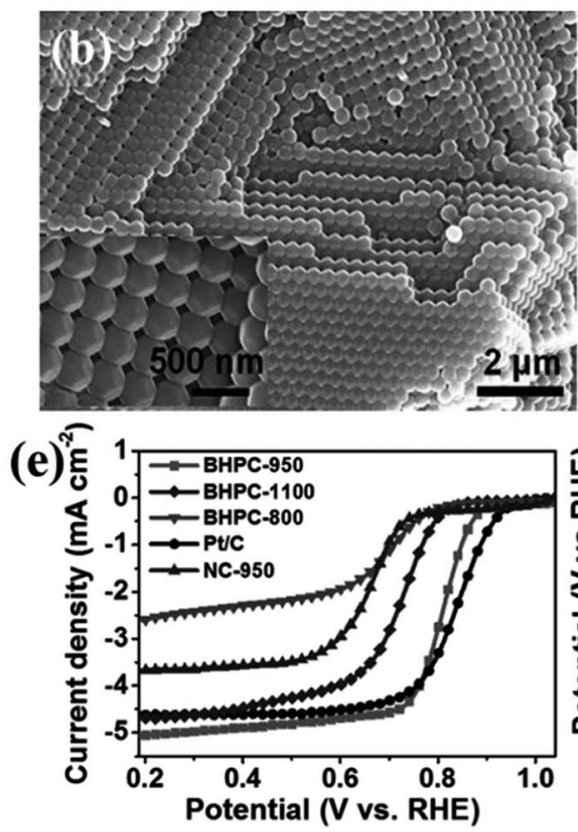

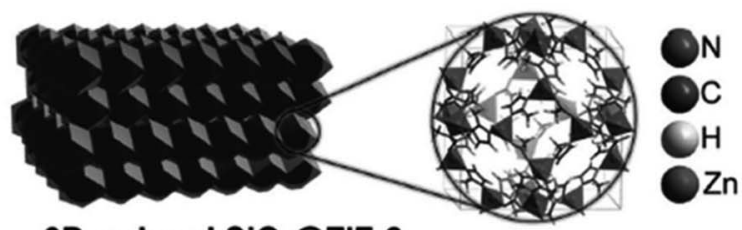

3D ordered $\mathrm{SiO}_{2} @ Z \mathrm{ZIF}-8$

Fig. 6 (a) Schematic representation of growing ZIF-8 crystals on an ordered silica template. SEM image of silica template with ZIF- 8 nanocrystals (b) before and (c) after carbonization. (d) HRETM image of the carbonized sample after etching the silica template. (e) LSV curves for the different carbonized samples in $0.1 \mathrm{M} \mathrm{KOH}$. (f) Polarization and power density curves of $\mathrm{Zn}$-air battery with $20 \mathrm{wt} \% \mathrm{Pt} / \mathrm{C}$ and BHPC-950 as the cathode, respectively. (Inset) Schematic representation of the basic configuration of a Zn-air battery. (g) Discharge curves of BHPC-950-based Zn-air batteries at various current densities, (inset) photograph of a "lovable" LED pattern powered by two BHPC-950 catalyzed Zn-air batteries connected in series. Reproduced with permission from ref. 147. Copyright 2017 Wiley.

morphology of NF@NC@C $\mathrm{CoFe}_{2} \mathrm{O}_{4} / \mathrm{C}$ NRAs plays an important role in accelerating the kinetics which in turn is the outcome of lower series resistance $\left(R_{\mathrm{S}}\right)$ and charge transfer resistance $\left(R_{\mathrm{CT}}\right)$ (Fig. 9(g)). NF@NC@Co/ $/ \mathrm{Fe}_{2} \mathrm{O}_{4}-\mathrm{C}$ NRAs also showed a stable chronopotentiometric response for $30 \mathrm{~h}$ (Fig. 9(h)). Polarization curves recorded before and after the durability test show very negligible change in the LSV profile, concluding the longevity of NF@NC-CoFe ${ }_{2} \mathrm{O}_{4} / \mathrm{C}$ NRAs (Fig. 9(i)).

In a recent work, a bimetallic ZIF-8 comprising both $\mathrm{Ni}$ and $\mathrm{Zn}$ has been carbonized between $700-1100{ }^{\circ} \mathrm{C}$ to obtain $\mathrm{Ni}$ induced tubular graphitic nanostructures (ZNDC). ZNDC-1100 shows excellent activity as a catalyst for OER, achieving benchmark $10 \mathrm{~mA} \mathrm{~cm}{ }^{-2}$ current density at a low overpotential of $1.67 \mathrm{~V}$, which is better than $\mathrm{IrO}_{2}{ }^{163}$

Such attempts, although few, delineated the potential of MOFs in fabricating successful OER electrocatalysts from MOF derived carbon materials.

\subsection{MOF derived electrocatalysts for hydrogen evolution reaction (HER)}

Hydrogen Evolution Reaction (HER) is an important half-cell reaction in water splitting. Hydrogen being the most important next-generation clean fuel, efficient HER can lead to the sustainable generation of hydrogen that can be used in fuel cells. It is a classic example of a two-electron process and the reaction occurring is as follows:

$$
2 \mathrm{H}^{+}+2 \mathrm{e} \rightarrow \mathrm{H}_{2}
$$

The benchmark catalyst in this case happens to be Pt. However in recent times MOF derived carbon materials have also been studied as electrocatalysts for this reaction.

The pyrolized derivatives of well-known MOFs, e.g., HKUST-1 (ref. 157) were initially explored for electrocatalysis without further modification (Fig. 10(a and b)). The octahedral shape of HKUST-1 (Fig. 10(c)) upon carbonization changed and adopted a distorted spherical "cauliflower-like" morphology (Fig. 10(d)), with particle sizes of $\sim 20 \mathrm{~nm}$ in its carbonized form regarded as $\mathrm{Cu} / \mathrm{NPC}$. EDS showed the presence of only $\mathrm{C}$ and $\mathrm{Cu}$ in $\mathrm{Cu} / \mathrm{NPC}$ and the BET surface area was calculated to be $\sim 1025 \mathrm{~m}^{2} \mathrm{~g}^{-1}$. Upon being coated on GCE, $\mathrm{Cu} / \mathrm{NPC}$ showed a decent activity as an electrocatalyst for HER in acidic medium producing a current density of $-10.66 \mathrm{~mA} \mathrm{~cm}^{-2}$ at a potential of $-1.0 \mathrm{~V}$ ( $v s$. RHE). As expected, its activity was much better than that in the 


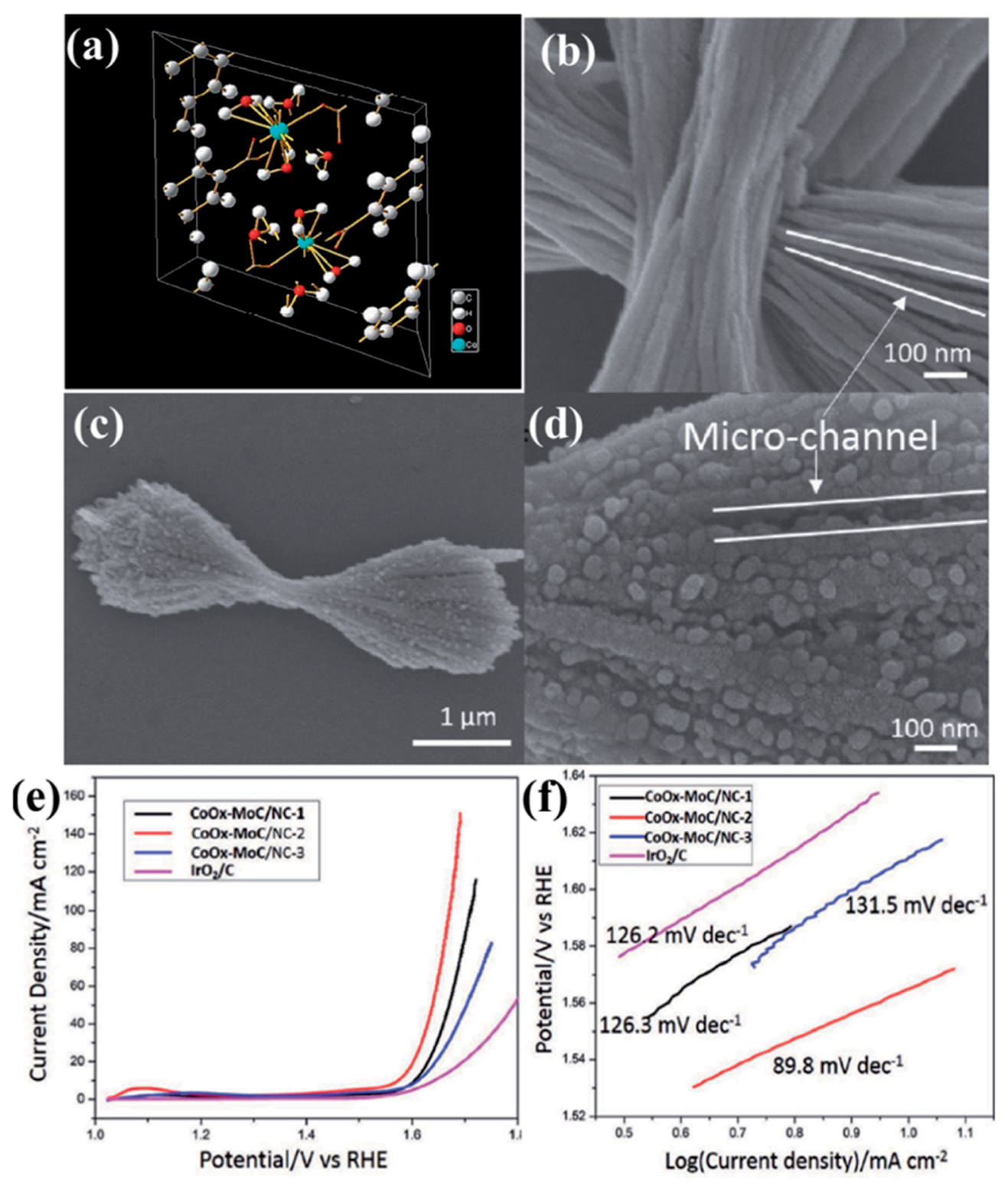

Fig. 7 (a) Crystallographic structure for the Co-MOF. Reproduced with permission from ref. 159. (b) FESEM images of the hybrid Co-Mo-MOF. (c and d) Carbonized product obtained by the pyrolysis of Co-Mo-MOF (e) LSV curves of different electrocatalysts at 1600 rpm (f) comparative Tafel slopes for the different carbonized products. Reproduced with permission from ref. 148. Copyright 2017 Wiley.

original HKUST-1. This has been attributed to the metallic $\mathrm{Cu}$, $\mathrm{CuO}$ and $\mathrm{Cu}_{2} \mathrm{O}$ present in $\mathrm{Cu} / \mathrm{NPC}$, unlike the strong covalently bonded $\mathrm{Cu}$ in the HKUST framework. Moreover the high BET surface area as well $\mathrm{H}_{2}$ adsorption capacity provides an added advantage to $\mathrm{Cu} / \mathrm{NPC}$. Although the resistance to Faradaic process is greater in $\mathrm{Cu} / \mathrm{NPC}$ than in HKUST-1 owing to the presence of $\mathrm{Cu}_{2} \mathrm{O}$, the overall catalytic activity is much better in $\mathrm{Cu} / \mathrm{NPC}^{150}$

In an extension to the afore-mentioned work, a novel catalyst containing $\mathrm{Cu}-\mathrm{Pd}$ bimetallic nanoparticles supported on a nanoporous carbon was used for HER. Here, HKUST-1 was prepared in both hydrothermal and electrochemical methods. Thereby, they were carbonized and some of the $\mathrm{Cu}$ replaced by Pd using galvanic replacement, also known as trans-metalation.
The composite material yielded from the electrochemically synthesized HKUST-1 (Cu-Pd/NPCC/EC (Fig. 10(e))) showed a much higher current density and lower overpotential than its hydrothermally synthesized counterpart (Fig. 10(f)). This has been attributed to the high specific surface area of $\mathrm{Cu}-\mathrm{Pd} /$ NPCC/EC. Moreover, the electrochemical synthesis controls the oxidation state of $\mathrm{Cu}$ by the application of a proper potential and also enhances the $\mathrm{Cu}$ content. ${ }^{151}$

$\mathrm{Xu}$ et al., presented a very simple and effective method of preparing HER electrocatalysts active in both acid and alkaline medium by carbonizing ZIF- 67 at $600{ }^{\circ} \mathrm{C}$ under $\mathrm{N}_{2}$ atmosphere to form $\mathrm{Co} / \mathrm{N}-\mathrm{C} .{ }^{152}$ A vacuum phosphosulfurization process in the presence of $\mathrm{P}$ and $\mathrm{S}$ powders led to the formation of CoPS $/ \mathrm{N}-$ C (Fig. 11(a)). Similar methods were used to prepare $\mathrm{CoP}_{2} / \mathrm{N}-\mathrm{C}$ 


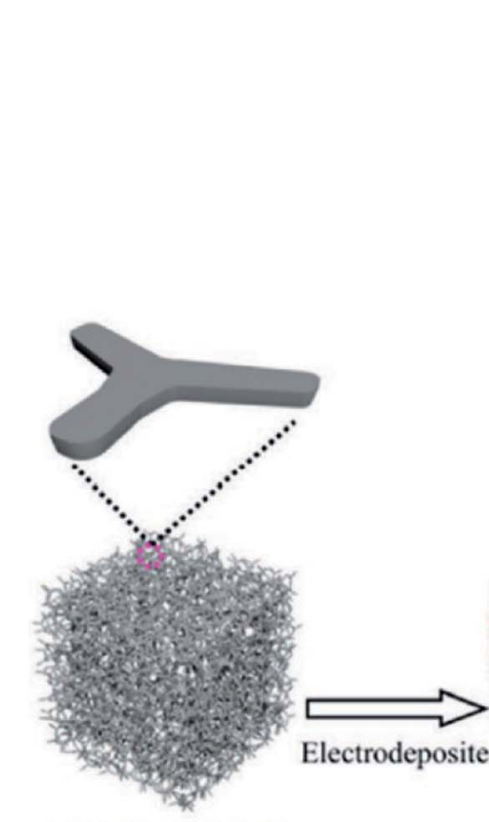

Nickel Foam (NF)

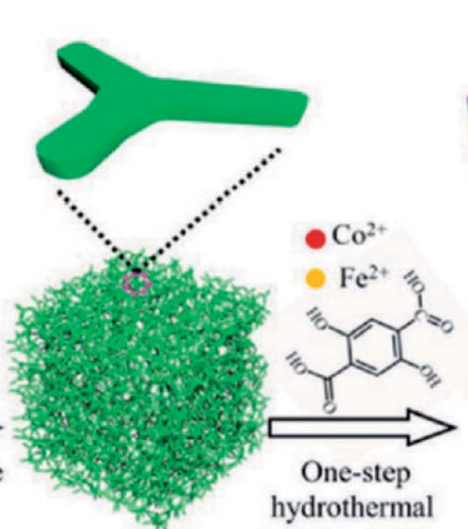

NF@PANI
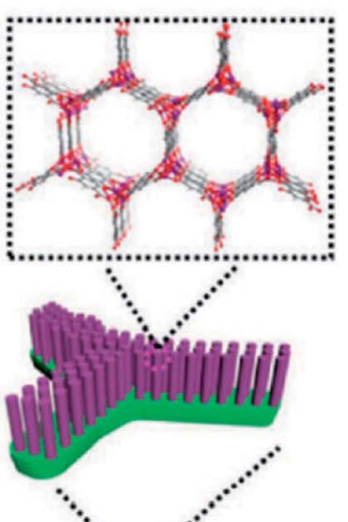

$\mathrm{OH}$
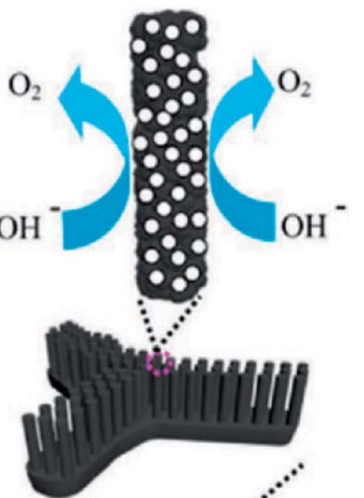

NF@PANI@MOF-74-Co/Fe NRAs

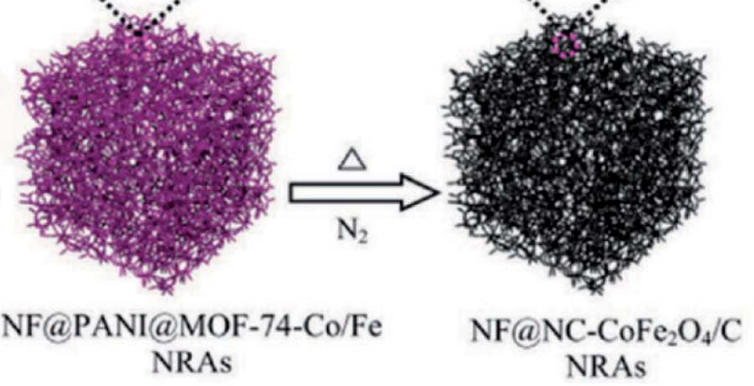

Fig. 8 Schematic representation of one-step PANI-assisted synthesis of a bimetal-organic framework NRAs and its derived porous $\mathrm{CoFe}{ }_{2} \mathrm{O}_{4} / \mathrm{C}$ NRAs. Reproduced with permission from ref. 149. Copyright 2017 Wiley.

and $\mathrm{CoS}_{2} / \mathrm{N}-\mathrm{C}$ nanocomposites for a comparative study. The ZIF-67 and all its derived nanocomposites were characterized by XRD, Raman spectroscopy, X-ray photoelectron spectroscopy which strongly attest the formation of CoPS/N-C with CoPS supported on N-doped carbon matrix. The polyhedral morphology of ZIF-67 was inherited by the CoPS/N-C with signs of structural collapse explained by the decrease in particle size caused due to the probable reconstruction of carbon framework during high temperature carbonization, phosphorization, sulfurization and phosphosulfurization processes (Fig. 11(b-d)). This shrinkage of carbon framework was also evident from the calculated BET surface areas (ZIF-67 $=1493 \mathrm{~m}^{2} \mathrm{~g}^{-1}, \mathrm{Co} / \mathrm{N}-\mathrm{C}=$ $317 \mathrm{~m}^{2} \mathrm{~g}^{-1}$ and $\left.\mathrm{CoPS} / \mathrm{N}-\mathrm{C}=69 \mathrm{~m}^{2} \mathrm{~g}^{-1}\right)$. Co, P, S, C, N and O in $\mathrm{CoPS} / \mathrm{N}-\mathrm{C}$ were distributed uniformly on the polyhedrons as evident from the microscopic images and elemental mapping (Fig. 11(e)). The electrocatalytic activities of ZIF-67, Co/N-C, $\mathrm{CoPS} / \mathrm{N}-\mathrm{C}, \mathrm{CoP}_{2} / \mathrm{N}-\mathrm{C}$ and $\mathrm{CoS}_{2} / \mathrm{N}-\mathrm{C}$ nanocomposites, towards HER were tested by casting them on a GCE and corresponding LSVs were tested in $0.5 \mathrm{M} \mathrm{H}_{2} \mathrm{SO}_{4}$ at a rotating speed of $2000 \mathrm{rpm}$. Pristine ZIF-67 was inactive whereas the nanocomposites showed a steep rise in the cathodic current, among which CoPS/ $\mathrm{N}-\mathrm{C}$ outperformed the $\mathrm{CoP}_{2} / \mathrm{N}-\mathrm{C}, \mathrm{CoS}_{2} / \mathrm{N}-\mathrm{C}$ and $\mathrm{Co} / \mathrm{N}-\mathrm{C}$. CoPS/ $\mathrm{N}-\mathrm{C}$ required an overpotential of $-80 \mathrm{mV} v s$. RHE to achieve a current density of $-10 \mathrm{~mA} \mathrm{~cm}{ }^{-2}$ (Fig. 11(f)). The Tafel slope analysis proposed a two-electron transfer process following Volmer-Heyrovsky mechanism of bimolecular adsorption and hydrogen evolution (Fig. 11(g)). Also, the low value of the slope $\left(69 \mathrm{mV} \mathrm{dec}^{-1}\right.$ ) supports the efficient reaction kinetics. To find out the reason behind this excellent catalytic activity, double- layer capacitance $\left(C_{\mathrm{dl}}\right)$ and charge transfer resistance $\left(R_{\mathrm{CT}}\right)$ were measured by $\mathrm{CV}$ and electrochemical impedance spectroscopy (EIS), respectively. The $C_{\mathrm{dl}}$ for CoPS/N-C was found to be the highest ( $21.55 \mathrm{mF} \mathrm{cm}^{-2}$ ) and $R_{\mathrm{CT}}$ was found to be the lowest $(4.8 \Omega)$ among the other nanocomposites, signifying larger surface area, more accessible active sites and faster Faradaic response and hence faster kinetics (Fig. 11(h and i)). LSV recorded before and after 1000 cycles of CV at $50 \mathrm{mV} \mathrm{s}^{-1}$, showed a negligible shift in the overpotential. All the above experiments were also carried out in alkaline medium $(1 \mathrm{M}$ $\mathrm{KOH}$ ) and $\mathrm{CoPS} / \mathrm{N}-\mathrm{C}$ was proven to be active towards HER with an overpotential of $-128 \mathrm{mV}$, with Tafel slope of $78 \mathrm{mV} \mathrm{dec}{ }^{-1}$.

$\mathrm{Wu}$ and co-workers demonstrated a method to preserve the framework by in situ confinement of species inside the pore which prevents the agglomeration of the active sites in the carbon matrix. ${ }^{160}$ A Cu-based MOF [HKUST-1; $\mathrm{Cu}_{3}(\mathrm{BTC})_{2}\left(\mathrm{H}_{2} \mathrm{O}\right)_{3}$ ] and a Mo-based POM $\left(\mathrm{H}_{3} \mathrm{PMo}_{12} \mathrm{O}_{40}\right)$ were coprecipitated to form octahedral nanocrystallites of NENU-5 where POMs are confined inside the pores of HKUST-1. Upon carbonization of NENU-5 at $800{ }^{\circ} \mathrm{C}$ under $\mathrm{N}_{2}$ atmosphere, Mo reacts with carbonaceous ligands to form $\mathrm{MoC}_{x}-\mathrm{Cu}$, whereas the presence of $\mathrm{Cu}^{2+}$ assists in the formation of $\mathrm{MoC}_{x}$ by getting reduced to $\mathrm{Cu}$. Finally, $\mathrm{MoC}_{x}-\mathrm{Cu}$ were converted to $\mathrm{MoC}_{x}$ by etching the metallic $\mathrm{Cu}$ on treating with ferric chloride solution. A pictorial representation of the scheme is shown in Fig. 12(a). The Mo included structure shows a visible colour change, and also changes in the PXRD pattern (Fig. 12(b)).

The FESEM images of NENU-5 and $\mathrm{MoC}_{x}$ show strikingly similar morphology (Fig. 12(c and d)). The high resolution 

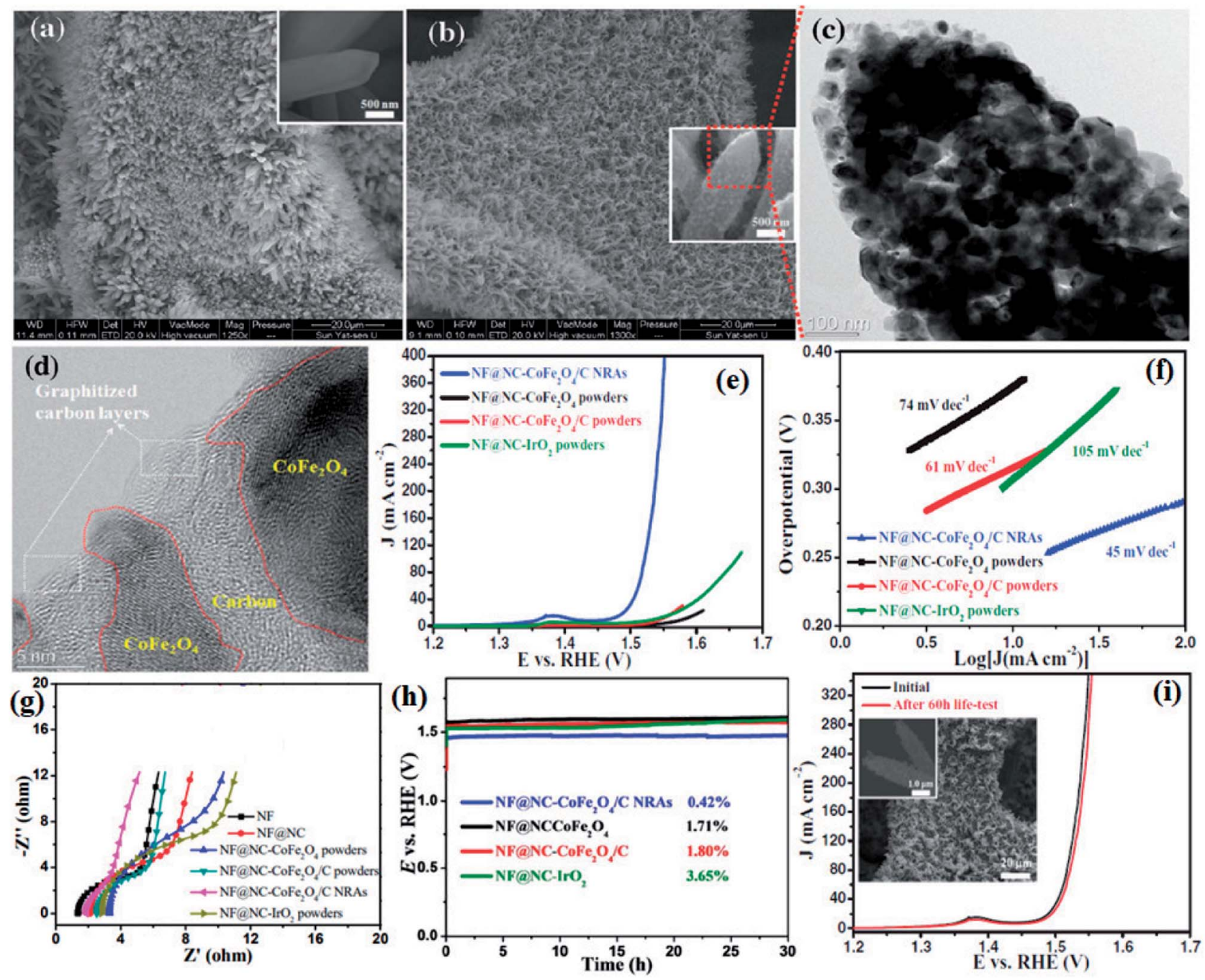

Fig. 9 (a) SEM image of MOF-74-Co/Fe nanorod array (NRAs) (inset) one magnified MOF-74-Co/Fe nanorod (b) SEM image of CoFe $\mathrm{O}_{4} / \mathrm{C}$ NRAs (inset) a magnified $\mathrm{CoFe}_{2} \mathrm{O}_{4} / \mathrm{C}$ nanorod. (c) TEM image of a $\mathrm{CoFe}_{2} \mathrm{O}_{4} / \mathrm{C}$ nanorod. (d) HRTEM image of CoFe $\mathrm{O}_{4}$ nanoparticles encapsulated by carbon layers. (e) Polarization curves, (f) Tafel plots, (g) electrochemical impedance spectroscopy (EIS) recorded at open circuit potential and (h) chronopotentiometry curves of $\mathrm{NF} a \mathrm{NC}-\mathrm{CoFe}_{2} \mathrm{O}_{4} / \mathrm{C}$ NRAs, NF@NC-CoFe $\mathrm{O}_{4}$ powders, NF@NC-CoFe $\mathrm{O}_{4} / \mathrm{C}$ powders, and NF@NC-IrO 2 powders in $1.0 \mathrm{M} \mathrm{KOH}$ solution. The chronopotentiometry was done at a current density of $10 \mathrm{~mA} \mathrm{~cm}^{-2}$. (i) $\mathrm{LSVs}_{\mathrm{S}}$ of NFaNC-CoFe $\mathrm{N}_{4} / \mathrm{C} \mathrm{NRAs}$ before and after $60 \mathrm{~h}$ durability test at $100 \mathrm{~mA} \mathrm{~cm}^{-2}$ (inset shows the SEM images of the catalyst after durability test). Reproduced with permission from ref. 149. Copyright 2017 Wiley.

transmission electron microscopy (HRTEM) image and the elemental mapping confirmed the uniform distribution of Mo nanoparticles with diameter of $\sim 5 \mathrm{~nm}$ embedded on the carbon matrix (Fig. 12(e and f)). The electrocatalytic activity of $\mathrm{MoC}_{x}-\mathrm{Cu}$ towards HER was studied in $0.5 \mathrm{M} \mathrm{H}_{2} \mathrm{SO}_{4}$ and $1 \mathrm{M} \mathrm{KOH}$. An overpotential of $25 \mathrm{mV}$ and $80 \mathrm{mV}$ is required to initiate a cathodic current in acidic and alkaline media, respectively (Fig. 12(g and h)). The corresponding Tafel slopes of $53 \mathrm{mV}$ $\mathrm{dec}^{-1}$ and $59 \mathrm{mV} \mathrm{dec}{ }^{-1}$ signify fast kinetics. The electrocatalyst also showed excellent stability in both the media (Fig. 12(i)). This excellent HER activity is attributed to the Pt like electronic properties of MoC, brought about by high porosity and also by the availability of more active sites. The confinement strategy explored here negates agglomeration of active sites, keeping them exposed and catalytically active. The homogeneity of the morphology and the mesoporosity facilitates the charge and mass transport and hence providing faster reaction kinetics. The in situ confinement strategy for preparing electrocatalyst also opens up opportunities to design and synthesize high performing nanostructured transition metal carbides. These reports establish that indeed it is possible to synthesize highly efficient catalysts for HER from MOF derivatives.

\section{Bifunctional electrocatalysts from MOF derived materials}

While the superior activity of a material in a particular electrochemical reaction, e.g., OER, ORR or HER, is of utmost importance, practical electrolyzers require efficiency in multiple reactions for real-time use. While bifunctionality in 
(a)
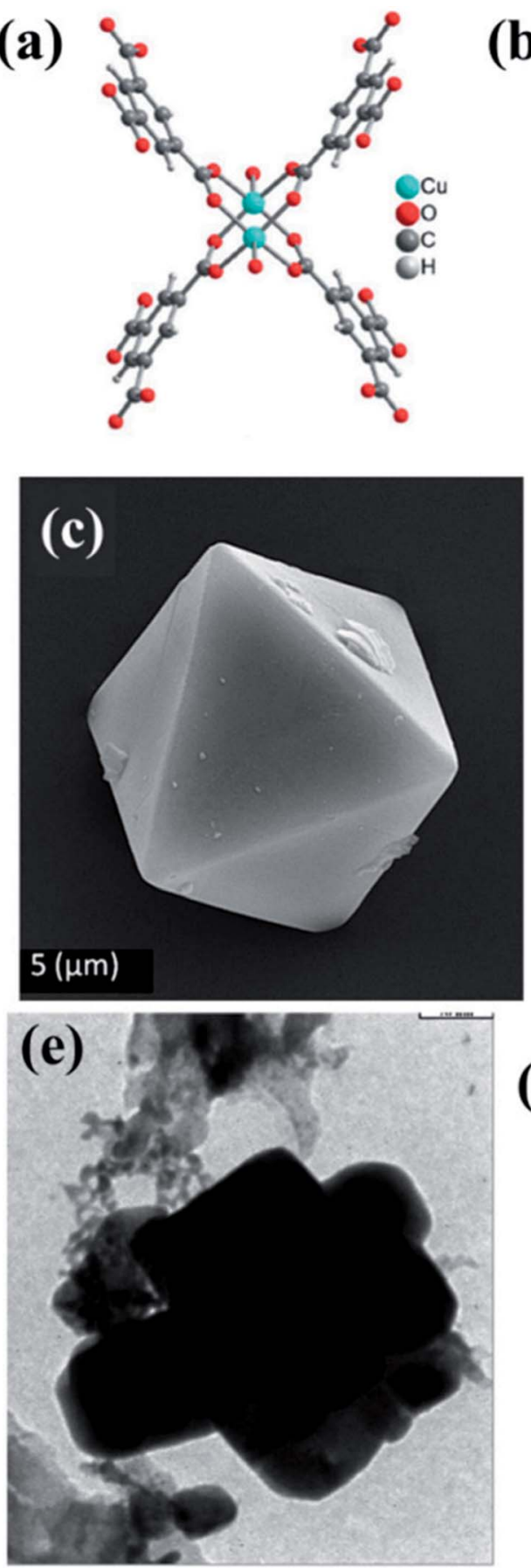
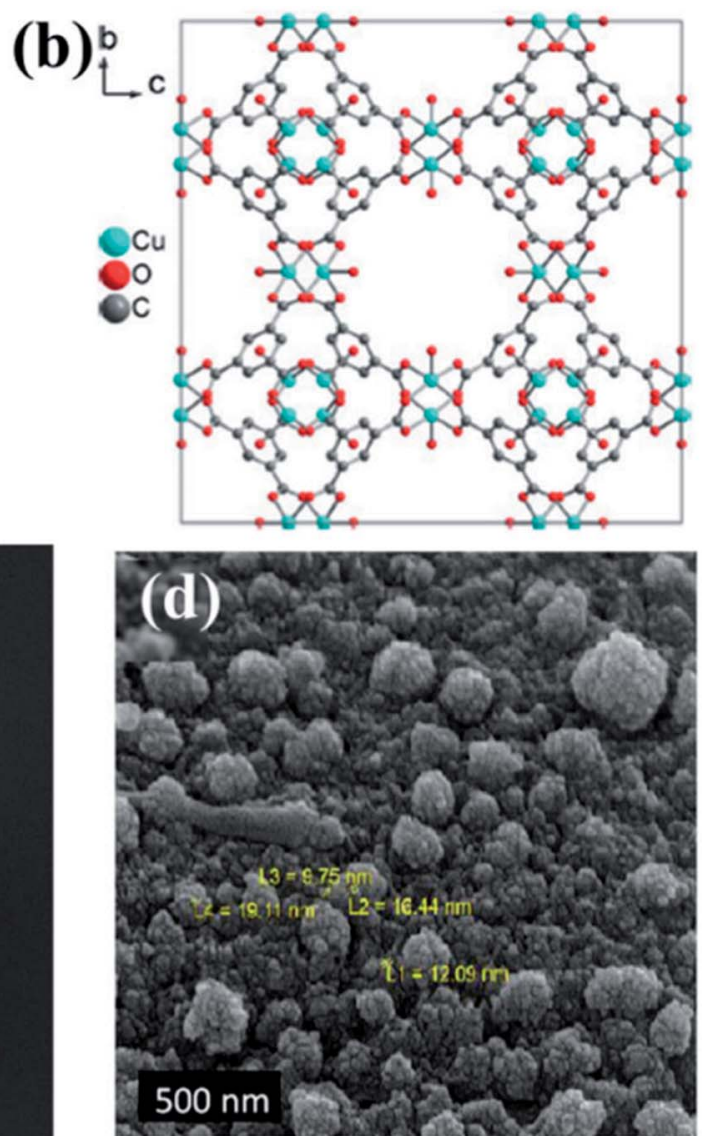

(f)

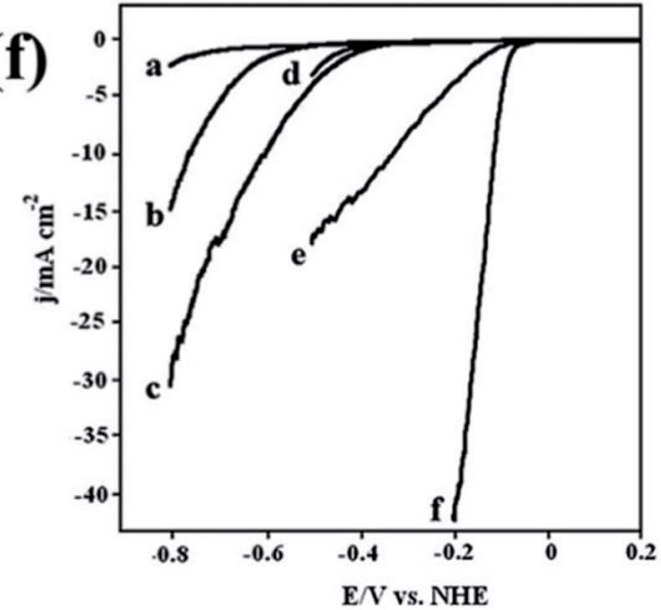

Fig. 10 (a) Asymmetric unit of HKUST-1. (b) Packing of HKUST-1 in a direction. Reproduced with permission from ref. 157. Copyright 2012 Wiley. (c) Pyramidal HKUST nanoparticle before carbonization. (d) HKUST-1 after carbonization. (e) TEM image of Cu-Pd/NPCC/EC. Reproduced with permission from ref. 150. Copyright 2015, Elsevier. (f) LSV scan for HER on (a) bare GCE, (b) Cu/NPCC/HT/GCE, (c) Cu/NPCC/EC/GCE, (d) Pd/ GCE, (e) $\mathrm{Cu}-\mathrm{Pd} / \mathrm{NPCC} / \mathrm{HT} / \mathrm{GCE}$ and (f) $\mathrm{Cu}-\mathrm{Pd} / \mathrm{NPCC} / \mathrm{EC} / \mathrm{GCE}$ in $0.5 \mathrm{M} \mathrm{H}_{2} \mathrm{SO}_{4}$ solution at $5 \mathrm{mV} \mathrm{s}^{-1}$. Reproduced with permission from ref. 151. Copyright 2018, Elsevier.

OER and HER is essential for a material to have practical use in electrochemical water splitting, bifunctionality in ORR and OER is important in reversible fuel cells and metal-air batteries. In the attempt to explore MOF derived electrocatalysts, a few bifunctional catalysts were also developed.

A commendable approach was reported by Qiao et al. who fabricated efficient bifunctional electrocatalysts by growing Co- naphthalenedicarboxylate $\left\{\mathrm{Co}\left(\mathrm{C}_{12} \mathrm{H}_{6} \mathrm{O}_{4}\right) \cdot\left(\mathrm{H}_{2} \mathrm{O}\right)_{4}\right\}$ framework on a $\mathrm{Cu}$ foil by hydrothermal methods at moderate temperature $\left(\sim 80{ }^{\circ} \mathrm{C}\right) .{ }^{153}$ As perceived from various microscopic techniques, the MOF grows on the $\mathrm{Cu}$ foil as arrays of nanowires with a diameter of $\sim 250 \mathrm{~nm}$. These when subjected to carbonization under $\mathrm{N}_{2}$ atmosphere resulted in porous hybrid carbon nanowires with $\mathrm{Co}_{3} \mathrm{O}_{4}$ nanoparticles $\left(\mathrm{Co}_{3} \mathrm{O}_{4} \mathrm{C}-\mathrm{NA}\right)$ (Fig. 13(a)). The 

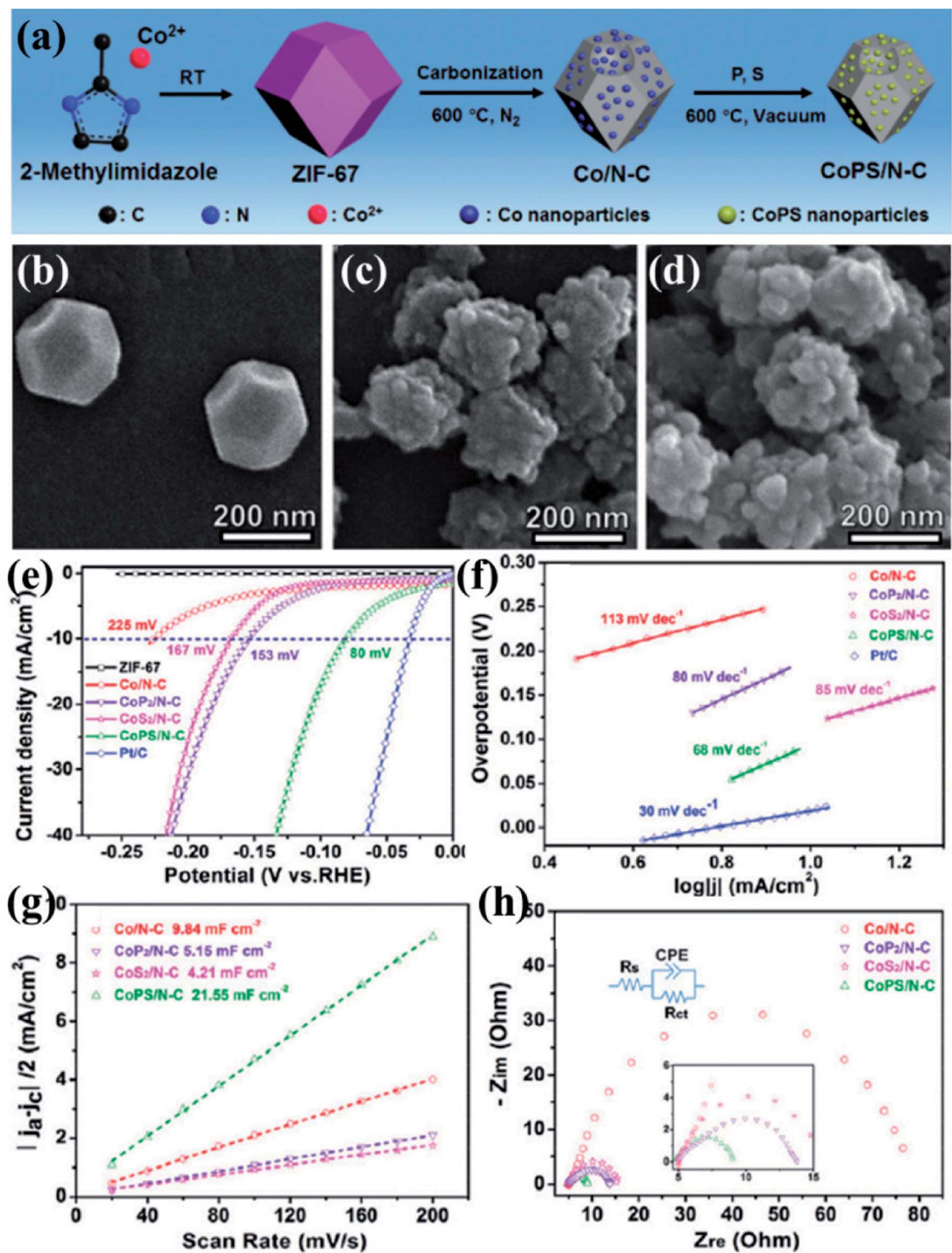

Fig. 11 (a) Schematic representation of ZIF-67 synthesis and its subsequent conversion to Co/N-C and CoPS/N-C nanocomposites. SEM images of (b) ZIF-67, (c) Co/N-C and (d) CoPS/N-C. (e) Elemental mapping of CoPS/N-C showing evenly distributed Co, P, S, C, N and O. (f) Polarization curves for HER in comparison with $\mathrm{Pt} / \mathrm{C}$ done in $0.5 \mathrm{M} \mathrm{H}_{2} \mathrm{SO}_{4}$. (g) Tafel plots for the corresponding polarization curves. (h) Nyquist plots (the inset shows the equivalent circuit used to simulate the Nyquist plots). Reproduced with permission from ref. 152. Copyright 2018 Royal Society of Chemistry.

microscopic images of the formed nanowires are shown in Fig. 13(b and c). Domains of crystalline $\mathrm{Co}_{3} \mathrm{O}_{4}$ demarcated by lattice fringes surrounded by amorphous phases were visible in HRTEM (Fig. 13(d and e)). $\mathrm{Co}_{3} \mathrm{O}_{4} \mathrm{C}-\mathrm{NA}$ grown on Cu-foil can be directly used as working electrode for studying the electrocatalytic activity towards OER without any further processing. The authors systematically studied the catalytic contribution from $\mathrm{Cu}$-foil, MOF and $\mathrm{Co}_{3} \mathrm{O}_{4} \mathrm{C}-\mathrm{NA}$. The polarization curve 

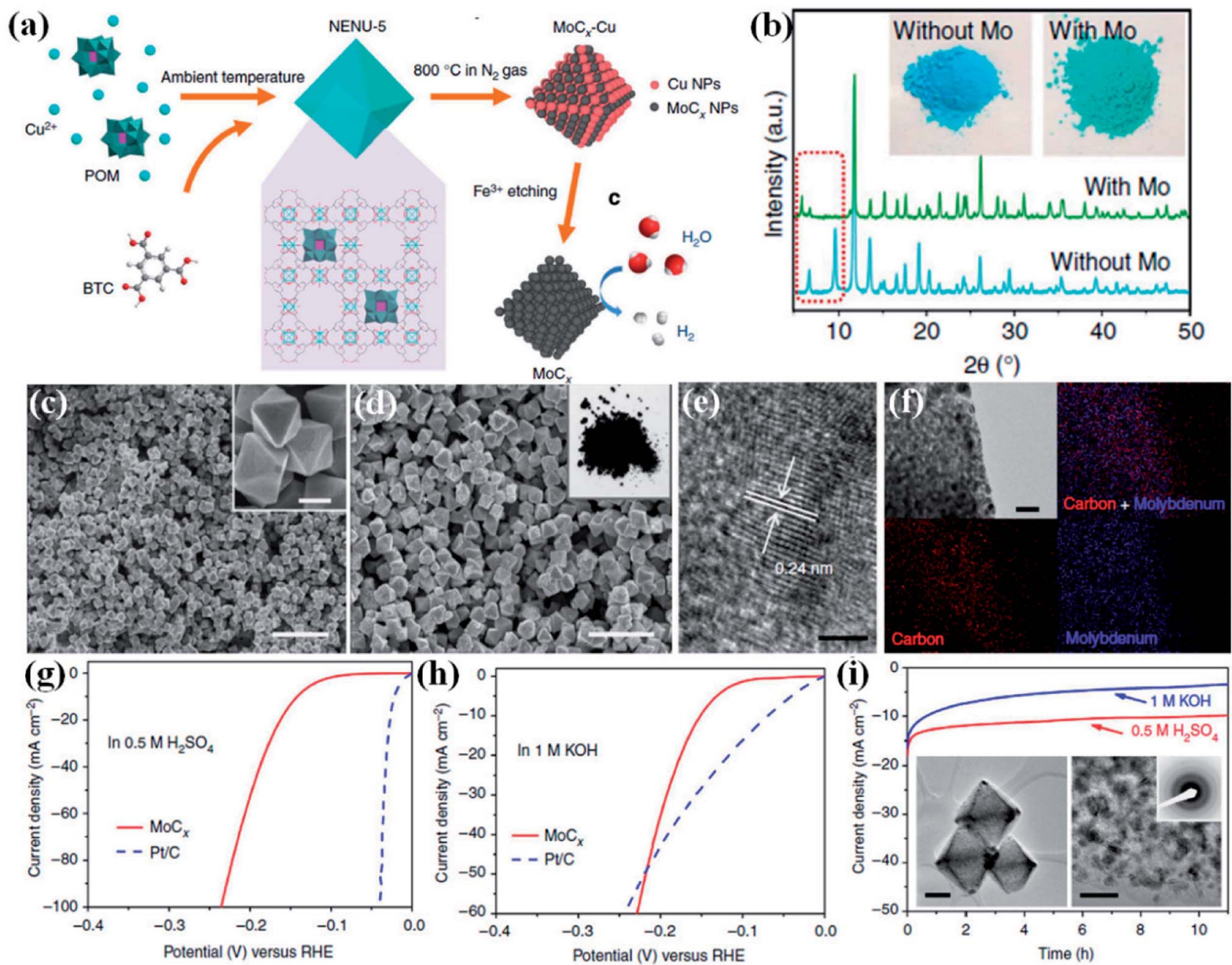

Fig. 12 (a) Schematic representation of the synthetic procedure for porous MoC $_{x}$ nano-octahedrons (b) XRD patterns of NENU-5 (with Mo) and HKUST-1 (without Mo). (Inset) the corresponding sample photographs. (c) FESEM image of NENU-5. (Inset) magnified image, scale bar 500 nm. (d) Porous $\mathrm{MoC}_{x}$ nano-octahedrons (inset) photograph. Scale bar, $2 \mu \mathrm{m}$. (e) HRTEM image (scale bar, $2 \mathrm{~nm}$ ) (f) elemental mapping (red: carbon; blue: molybdenum; scale bar, $50 \mathrm{~nm}$ ) of porous $\mathrm{MoC}_{x}$ nano-octahedrons. Polarization curves at $2 \mathrm{mV} \mathrm{s}^{-1}$ in (g) $0.5 \mathrm{M} \mathrm{H}_{2} \mathrm{SO}_{4}$ and (h) in $1 \mathrm{M} \mathrm{KOH}$. (i) Chronoamperometric curves under at an overpotential of $170 \mathrm{mV}$ in $0.5 \mathrm{M} \mathrm{H}_{2} \mathrm{SO}_{4}$ and $180 \mathrm{mV}$ in $1 \mathrm{M} \mathrm{KOH}$ (insets) TEM images and SAED pattern after 5000 potential sweeps in $0.5 \mathrm{M} \mathrm{H}_{2} \mathrm{SO}_{4}$. Scale bars: left inset $200 \mathrm{~nm}$ and right inset $20 \mathrm{~nm}$. Reproduced from ref. 160 in accordance with Creative Commons Attribution 4.0 International License.

recorded in $0.1 \mathrm{M} \mathrm{KOH}$ shows both $\mathrm{MOF}$ and $\mathrm{Co}_{3} \mathrm{O}_{4} \mathrm{C}-\mathrm{NA}$ to be active for OER (Fig. 13(f)). The corresponding Tafel plots are shown in Fig. 13(g). However, the pristine MOF showed a much lesser activity with the onset at $\sim 1.55 \mathrm{~V} v s$. RHE, whereas $\mathrm{Co}_{3} \mathrm{O}_{4} \mathrm{C}-\mathrm{NA}$ showed an onset at $\sim 1.47 \mathrm{~V} v$ s. RHE. $\mathrm{Co}_{3} \mathrm{O}_{4} \mathrm{C}-\mathrm{NA}$ is not only active towards OER but are also active towards ORR and selectively produces water as the product, following a four electron pathway (Fig. 13(h)). This exceptional catalytic behavior arises due to a complex synergistic effect between $\mathrm{Co}_{3} \mathrm{O}_{4}$ and $\mathrm{C}$ which causes the active Co sites to be more electrophilic, thereby facilitating the adsorption and oxidation of $\mathrm{OH}^{-}$ groups, showing enhanced OER activity in alkaline solutions. Also, the nanowire morphology of the catalysts assists in fast electron transfer. The nanowire morphology is also particularly advantageous in providing swift electrolyte penetration, whereas the mesopores assist the access of reactants in the electrolyte to the active sites. The nanowire morphology also helps in the faster release of the evolved $\mathrm{O}_{2}$. The most noteworthy advantage is growing the catalyst on conducting supports which ensures better adhesion between nanowire arrays and substrates, greatly enhancing the electron transport, structural stability, without the use of binders and conductive fillers. Owing to this fast kinetics, $\mathrm{Co}_{3} \mathrm{O}_{4} \mathrm{C}-\mathrm{NA}$ shows a Tafel slope much smaller than benchmark $\mathrm{IrO}_{2} / \mathrm{C}$ for OER.

Recently, we have reported synthesis and detailed characterization of an efficient and stable bi-functional electrocatalyst derived from a $3 \mathrm{D}$ metal-organic framework $\left\{\left[\mathrm{Co}(\mathrm{bpe})_{2}(-\right.\right.$ $\left.\left.\left.\mathrm{N}(\mathrm{CN})_{2}\right)\right] \mathrm{N}(\mathrm{CN})_{2} \cdot 5 \mathrm{H}_{2} \mathrm{O}\right\}$ (Co-MOF), (bpe $=1,2$-bis(4-pyridyl) ethane and $\mathrm{N}(\mathrm{CN})_{2}{ }^{-}=$dicyanamide) (Fig. 14(a)). ${ }^{121}$ The 3D framework of Co-MOF is composed of bridging be linkers which forms a $2 \mathrm{D}\left[\mathrm{Co}(\mathrm{bpe})_{2}\right]^{2+}$ layer and this is further pillared by $\mathrm{N}(\mathrm{CN})_{2}{ }^{-}$anions (Fig. 14(b)). The presence of large no of $\mathrm{Co}^{\mathrm{II}}-$ 
(a)

$\mathrm{N}_{6}$ moieties in the structure could lead to the formation of electrochemical active $\mathrm{M}-\mathrm{N}-\mathrm{C}$ sites. This Co-MOF was chosen as a carbonization template due to two reasons, (a) the presence of electroactive $\mathrm{Co}^{\mathrm{II}}$ metal ion, which can also catalyze organic precursors to form carbon nanotube under pyrolyzing condition at $\mathrm{H}_{2}$ atmosphere; (b) secondly, the presence of $\mathrm{N}(\mathrm{CN})_{2}$, a well known chemical precursor for $\mathrm{g}-\mathrm{C}_{3} \mathrm{~N}_{4}$ that can lead to the formation of $\mathrm{N}$-doped graphitic nanostructures. The two different catalysts were prepared by pyrolyzing Co-MOF at different conditions. Pyrolyzing at $800{ }^{\circ} \mathrm{C}$ under Ar atmosphere and at $800{ }^{\circ} \mathrm{C}$ under $\mathrm{H}_{2} / \mathrm{Ar}$ atmosphere resulted in Co-NCNT-Ar and Co-NCNT- $\mathrm{H}_{2}$ (NCNT = nitrogen doped carbon nanotube), respectively. Furthermore, Co-NCNT- $\mathrm{H}_{2}$ was calcined in air at $250{ }^{\circ} \mathrm{C}$ to obtain $\mathrm{Co}_{3} \mathrm{O}_{4} @ \mathrm{Co} / \mathrm{NCNT}$ composite material. Both the carbonized materials were characterized by PXRD, Raman spectroscopy, XPS, FESEM and TEM techniques. XRD pattern of Co-NCNT-Ar suggests the presence of metallic cubic Co phase on the regular graphitic carbon (Fig. 14(c)). Raman spectra showed $\mathrm{D}$ and $\mathrm{G}$ bands and their ratio suggests a high degree of graphitization in Co-NCNT-Ar and $\mathrm{Co}_{3} \mathrm{O}_{4} @ \mathrm{Co} / \mathrm{NCNT}$ (Fig. 14(d)). Raman spectra of $\mathrm{Co}_{3} \mathrm{O}_{4} @ \mathrm{Co} / \mathrm{NCNT}$ also showed the bands characteristics of typical $\mathrm{Co}_{3} \mathrm{O}_{4}$ spinel phase. XPS survey spectra for both the composite materials showed the presence of $\mathrm{Co}, \mathrm{C}, \mathrm{N}$ and $\mathrm{O}$. Along with metallic $\mathrm{Co}$, the presence of spinel like $\mathrm{Co}-\mathrm{N}_{4}, \mathrm{Co}(\mathrm{Co})_{4}$ and $\mathrm{Co}-\mathrm{N}-\mathrm{C}$ was also realized from XPS spectra (Fig. 14(e)). The detailed morphological feature of the carbonized product was realized from FESEM and TEM imaging. The microscopic study showed that in Co/NCNT$\mathrm{Ar}$, the Co nanoparticles are embedded in a continuous selfcoiled $\mathrm{N}$-doped carbon nanotube matrix, where the average diameter of Co nanoparticles and nanotubes are in the range of 50-110 nm and 50-200 nm, respectively (Fig. 14(f)). HRTEM showed lattice fringes with spacing of about $0.209 \mathrm{~nm}$ which corresponds to the $\{111\}$ of the cubic metal structure. Pyrolysis under $\mathrm{H}_{2}$ atmosphere also led to the formation of self-coiled dense N-doped carbon nanotube where metallic Co nanoparticles $(40-50 \mathrm{~nm})$ are embedded. After calcination in air, TEM images revealed the formation of core-shell nanoparticles $\mathrm{Co}_{3} \mathrm{O}_{4} @ \mathrm{Co}$ encapsulated in a CNT matrix. The length and diameter of the nanotubes are in the range of 100-200 nm and 10-20 nm, respectively. The lattice fringe of the outer shell of $\mathrm{Co}_{3} \mathrm{O}_{4} @ \mathrm{Co}$ nanoparticles is $0.46 \mathrm{~nm}$ which is characteristic cubic $\{111\}$ structure of $\mathrm{Co}_{3} \mathrm{O}_{4}$ and higher than that of $\mathrm{Co}(0.209$ $\mathrm{nm}$ ) (Fig. 14(g)). The permanent porosity was measured by the $\mathrm{N}_{2}$ adsorption study at $77 \mathrm{~K}$ to elucidate the textural parameters (Fig. 14(h)). Both Co-NCNT-Ar and $\mathrm{Co}_{3} \mathrm{O}_{4} @$ Co-NCNT showed typical type IV isotherm with BET surface area of 58 and $118 \mathrm{~m}^{2}$ $\mathrm{g}^{-1}$, respectively. Both the samples showed wide pore size distribution $(2-30 \mathrm{~nm})$. Electrochemical ORR and OER activities

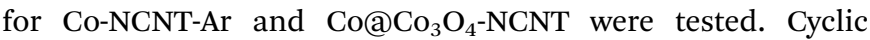


(a)

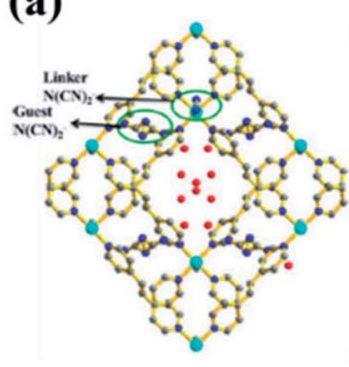

Co-MOF-1

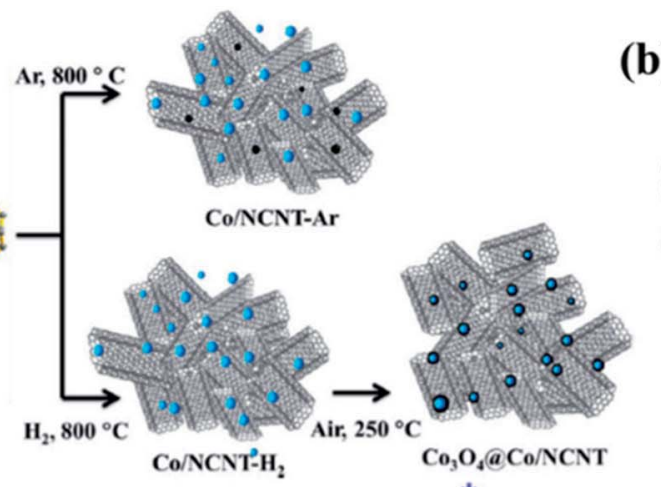

(d)
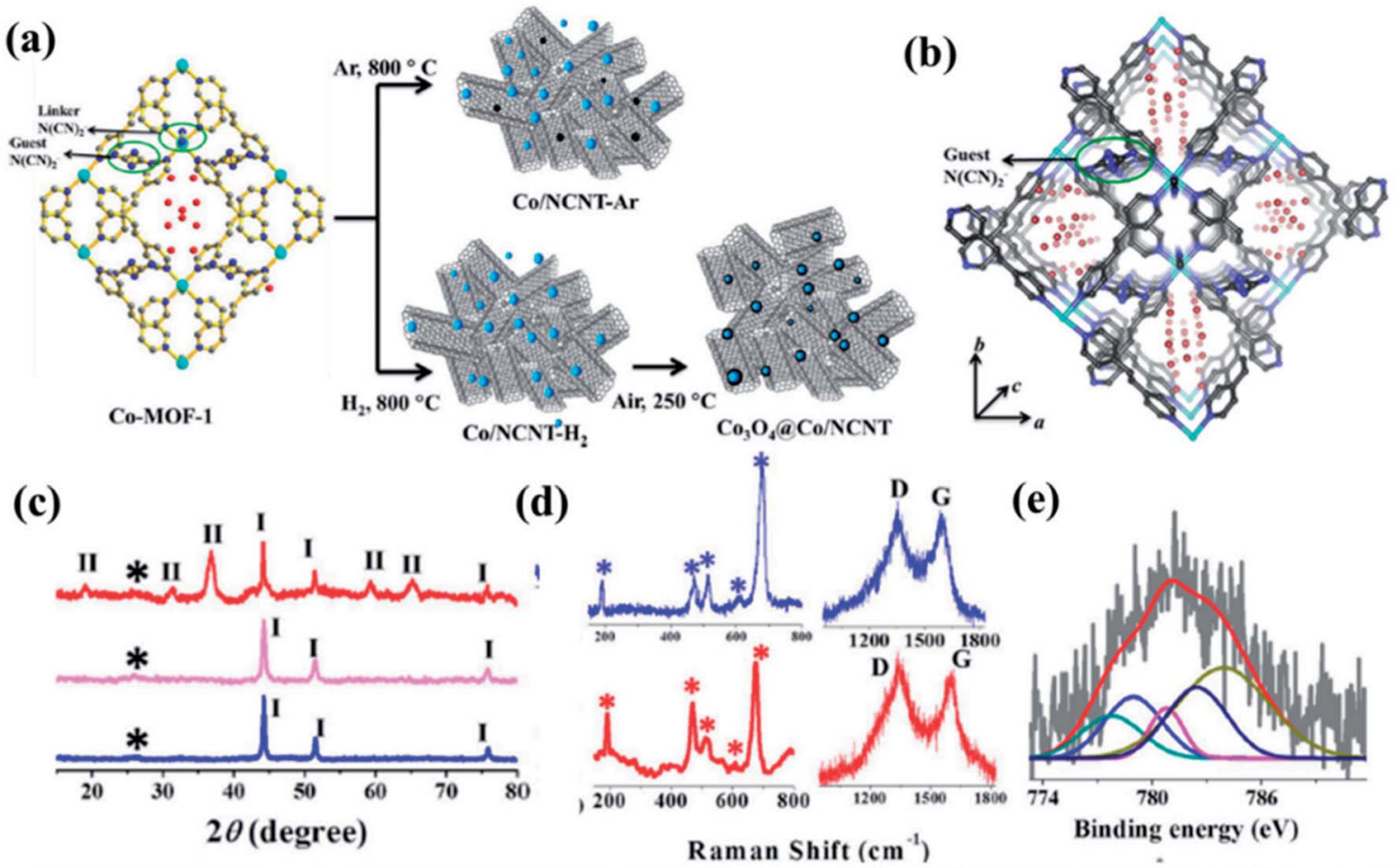

(e)
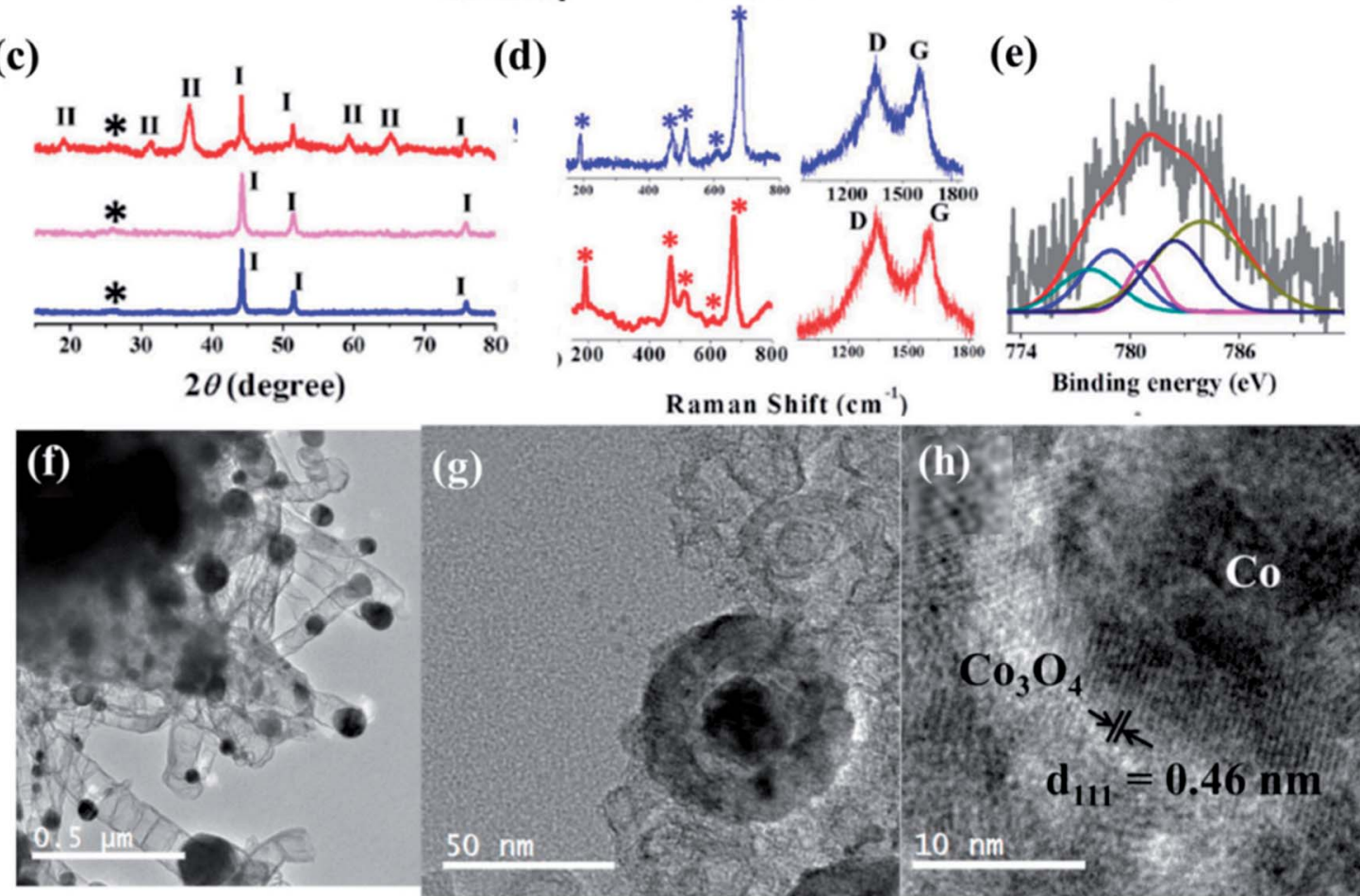

(energy (ev)

Fig. 14 (a) Schematic representation of the carbonization of Co MOF. (b) N-rich 3D interpenetrated framework of Co MOF [cyan = Co, blue: N, grey: C, red: oxygen]; the small circle represents the guest $\mathrm{N}(\mathrm{CN})_{2}{ }^{-}$and the red sticks represent free guest $\mathrm{N}(\mathrm{CN})_{2}{ }^{-}$anions, red balls represent guest water molecules (c) PXRD pattern of Co/NCNT-Ar (blue), Co/NCNT- $\mathrm{H}_{2}$ (pink), and $\mathrm{CO}_{3} \mathrm{O}_{4}$ (aCo/NCNT (red); *, I, II denote the graphitic (002) peak, Co peaks, and $\mathrm{Co}_{3} \mathrm{O}_{4}$ peaks, respectively; (d) Raman spectra of Co/NCNT-Ar (blue) and $\mathrm{Co}_{3} \mathrm{O}_{4}\left(\mathrm{CCo} / \mathrm{NCNT}\right.$ (red) showing Co $3 \mathrm{O}_{4}$ phase, along with the characteristic $D$ and $G$ bands. (e) Co2p spectrum from XPS. (f) TEM image of Co/NCNT-Ar. (g) Co $3 \mathrm{O}_{4}(\mathrm{aCo}$ core-shell nanoparticle embedded in a NCNT matrix in $\mathrm{CO}_{3} \mathrm{O}_{4} \mathrm{QCO} / \mathrm{NCNT}$; (h) HRTEM image of a single $\mathrm{CO}_{3} \mathrm{O}_{4}$ @Co nanoparticle showing lattice fringes. Reproduced with permission from ref. 121. Copyright 2017 Wiley.

voltammetry (CV) in $\mathrm{O}_{2}$ saturated $0.1 \mathrm{M} \mathrm{KOH}$ solution for CoNCNT-Ar and $\mathrm{Co}_{3} \mathrm{O}_{4} @ \mathrm{Co} / \mathrm{NCNT}$ was measured and showed good catalytic activity towards ORR at $\approx 0.87$ and $0.9 \mathrm{~V}$ ( $v s$. RHE), respectively(Fig. 15(a and b)). LSV of $\mathrm{Co}_{3} \mathrm{O}_{4} @ \mathrm{Co} / \mathrm{NCNT}$ using a RDE electrode at different rotation speeds revealed a remarkable catalytic performance for ORR affording a current density of $-1 \mathrm{~mA} \mathrm{~cm}{ }^{-2}$ at low overpotential of $0.88 \mathrm{~V}$ (onset $0.93 \mathrm{~V} v s$. RHE), and this value is 0.83 for Co-NCNT-Ar (onset at $0.9 \mathrm{~V}$ vs. RHE). $\mathrm{Co}_{3} \mathrm{O}_{4} @ \mathrm{Co} / \mathrm{NCNT}$ reveals a very close ORR activity to that of commercial Pt/C (Fig. 15(c and d)). KouteckyLevich (K-L) plots suggested first order reaction kinetics with respect to the dissolved $\mathrm{O}_{2}$ concentration and number of electrons transferred $(n)$ per $\mathrm{O}_{2}$ molecule during the ORR to be in the range of 3.92 to 3.96 suggesting the reduction of $\mathrm{O}_{2}$ predominantly through the 4 electron transfer pathway. Interestingly Co-NCNT-Ar showed 2 electron transfer pathway. RRDE measurement further confirmed it based on the percentage of $\mathrm{H}_{2} \mathrm{O}_{2}$ production (Fig. 15(e)). Co-NCNT-Ar showed about 54\% $\mathrm{H}_{2} \mathrm{O}_{2}$ production in the entire potential range $(0.8$ to $0.3 \mathrm{~V} v s$. RHE) and $\mathrm{Co}_{3} \mathrm{O}_{4} @$ @o-NCNT showed only $1 \% \mathrm{H}_{2} \mathrm{O}_{2}$ production. The relatively lower Tafel slope of $61 \mathrm{mV} \mathrm{dec}^{-1}$ for $\mathrm{Co}_{3} \mathrm{O}_{4} @ \mathrm{Co}$ NCNT compared to Co-NCNT-Ar $\left(74 \mathrm{mV} \mathrm{dec}^{-1}\right)$ indicating faster reaction kinetics for the former (Fig. 15(f)).

OER activity is also observed to be superior for $\mathrm{Co}_{3} \mathrm{O}_{4} @ \mathrm{Co}-$ NCNT compared to Co-NCNT-Ar as the former attained a current density of $10 \mathrm{~mA} \mathrm{~cm}{ }^{-2}$ at a potential of $1.61 \mathrm{~V} v s$. RHE, whereas later reached the same current density at $1.76 \mathrm{~V}$ at 1600 rpm (Fig. 16(a)). In a similar condition $\mathrm{RuO}_{2}$ and $\mathrm{IrO}_{2}$ 

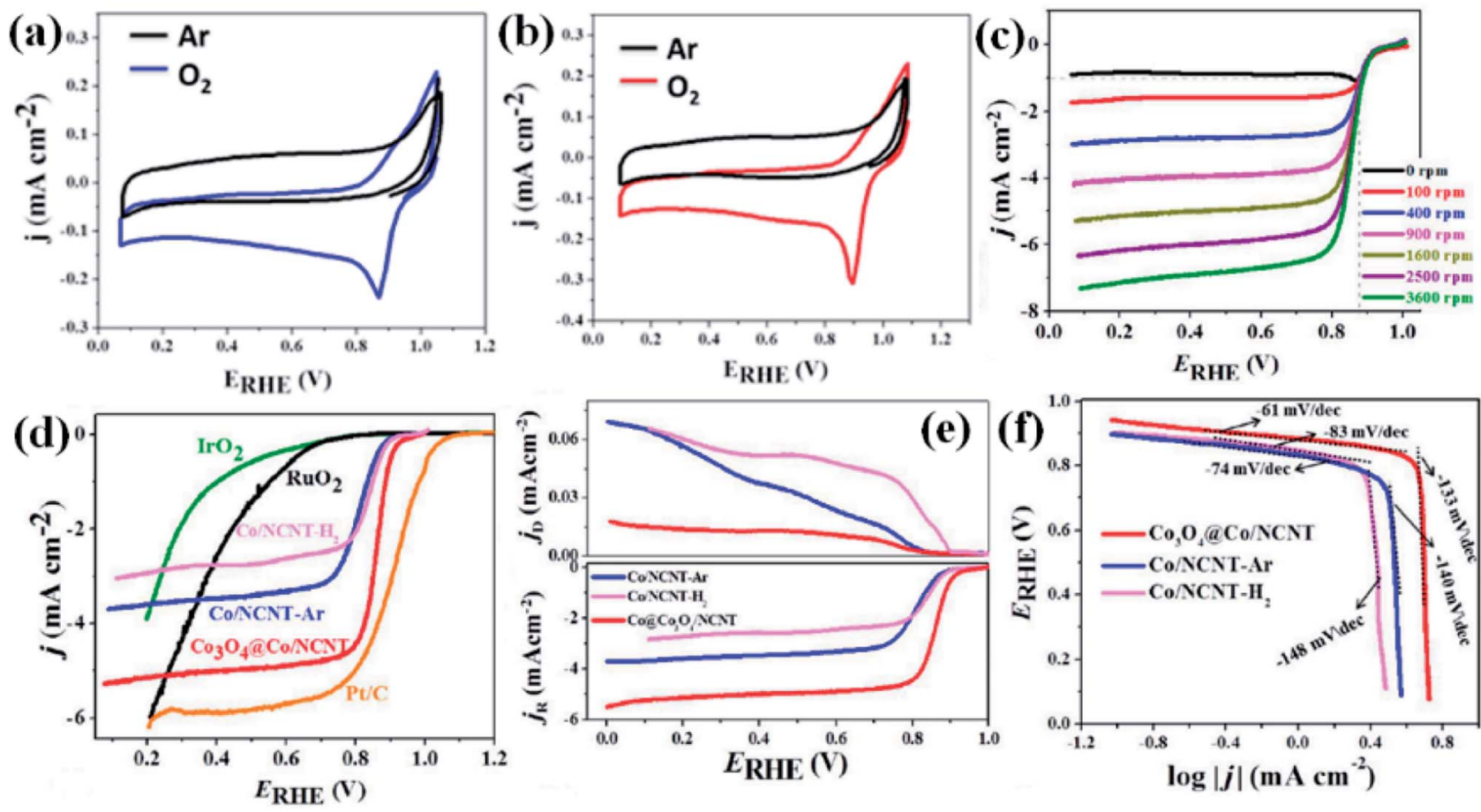

Fig. $15 \mathrm{CVs}$ for (a) Co/NCNT-Ar and (b) $\mathrm{CO}_{3} \mathrm{O}_{4} \mathrm{QCO} / \mathrm{NCNT}$ recorded at a scan rate of $5 \mathrm{mV} \mathrm{s}^{-1}$ in $\mathrm{O}_{2}$-saturated and $\mathrm{Ar}$-saturated $0.1 \mathrm{M} \mathrm{KOH}$ solution; (c) LSV curves recorded at various rotation speeds for $\mathrm{CO}_{3} \mathrm{O}_{4} \mathrm{QCO} / \mathrm{NCNT}$; (d) iR-corrected linear sweep voltammograms of different electrocatalysts collected at $1600 \mathrm{rpm}$ in $\mathrm{O}_{2}$-saturated $0.1 \mathrm{M} \mathrm{KOH}$ solution; (e) RRDE polarization curves for the ORR at $1600 \mathrm{rpm}$ for Co/NCNT$\mathrm{H}_{2}$, Co/NCNT-Ar and $\mathrm{CO}_{3} \mathrm{O}_{4} \mathrm{QCO} / \mathrm{NCNT}$; (f) ORR Tafel slopes of Co/NCNT-Ar, Co/NCNT-H 2 and Co $\mathrm{O}_{4} \mathrm{CCO} / \mathrm{NCNT}$. Reproduced with permission from ref. 121. Copyright 2017 Wiley.

exhibited 1.64 and $1.69 \mathrm{~V}$ (vs. RHE), respectively suggesting $\mathrm{Co}_{3} \mathrm{O}_{4} @$ @o-NCNT surpasses the benchmark catalysts (Fig. 16(a)). The Tafel slopes for the OER are $58.7 \mathrm{mV}$ per decade and $80 \mathrm{mV}$ per decade for $\mathrm{Co}_{3} \mathrm{O}_{4} @ \mathrm{Co}-\mathrm{NCNT}$ and CoNCNT-Ar, respectively, indicating reaction kinetics substantially faster for the former (Fig. 16(b)). Interestingly the overpotential difference between ORR (at current density of $-1 \mathrm{~mA}$ $\mathrm{cm}^{-2}$ ) and OER (at current density of $10 \mathrm{~mA} \mathrm{~cm}{ }^{-2}$ ) is about $0.73 \mathrm{~V}$, indicating high efficiency of $\mathrm{Co}_{3} \mathrm{O}_{4} @ \mathrm{Co}-\mathrm{NCNT}$ as ORR and OER bifunctional catalyst (Fig. 16(c)). This is an important parameter for evaluating the bifunctionality for a reversible oxygen electrode. This value is lowest among all the state of art catalysts. Furthermore chronoamperometric stability measurement suggested no significant decline in the current in the course of $30-40 \mathrm{~h}$ of continuous polarization, indicating high stability of both the catalyst (Fig. 16(d)). The high catalytic activity for $\mathrm{Co}_{3} \mathrm{O}_{4} @ \mathrm{Co}-\mathrm{NCNT}$ was attributed to the high surface area, presence of highly active sites and the synergistic interaction between conductive metallic Co cores and the semi conductive $\mathrm{Co}_{3} \mathrm{O}_{4}$ shell. All these parameters facilitate an easy mass diffusion and faster charge transfer in the NCNT network.

In a similar work by Muhler $e t$ al., bifunctionality in OER and ORR was demonstrated based on core-shell $\mathrm{Co@} \mathrm{Co}_{3} \mathrm{O}_{4}$ nanoparticles embedded in CNT grafted N-doped polyhedral obtained by the pyrolysis of ZIF-67. ${ }^{120}$ In this case, in the carbonized form, polyhedrons containing Co nanoparticles are wrapped in few layers of $\mathrm{CNT}$. The $\mathrm{Co}_{0} \mathrm{Co}_{3} \mathrm{O}_{4}$ particles are wrapped in graphene like highly graphitized carbon sheets. The width of the $\mathrm{Co}_{3} \mathrm{O}_{4}$ shell can be controlled by the time of calcination of the sample in $\mathrm{O}_{2}$ environment and two such samples were prepared with calcination times of 2 and $6 \mathrm{~h}$ respectively (Co@ $\mathrm{Co}_{3} \mathrm{O}_{4} / \mathrm{NC}-1$ and $\mathrm{Co} @ \mathrm{Co}_{3} \mathrm{O}_{4} / \mathrm{NC}-2$ ). While $\mathrm{Co@} \mathrm{Co}_{3} \mathrm{O}_{4} / \mathrm{NC}-1$ shows a better activity in ORR, $\mathrm{Co} @ \mathrm{Co}_{3} \mathrm{O}_{4} / \mathrm{NC}-$ 2 has a better performance in OER, with a current density of $-10 \mathrm{~mA} \mathrm{~cm} \mathrm{~cm}^{-2}$ achieved merely at $1.64 \mathrm{~V}$. However, upon considering bifunctionality, it is observed that overall $\mathrm{Co} @ \mathrm{Co}_{3} \mathrm{O}_{4} / \mathrm{NC}-1$ is a more efficient electrocatalyst, with comparable activity in ORR with Pt/C and in OER with $\mathrm{IrO}_{2}$ and $\mathrm{Pt} / \mathrm{C}$. As suggested in this work, the small overvoltage in bifunctionality between ORR and OER translates in to energy saving of at least $150 \mathrm{mV}$ and $100 \mathrm{mV}$ for $\mathrm{Co@} \mathrm{Co}_{3} \mathrm{O}_{4} / \mathrm{NC}-1$ and $\mathrm{Co@} \mathrm{Co}_{3} \mathrm{O}_{4} / \mathrm{NC}-2$, respectively. ${ }^{120}$

An attempt towards fabricating bifunctional catalysts was also made by carbonizing ZIF-67 at various temperatures from $600-2000{ }^{\circ} \mathrm{C}$ under Ar atmosphere. ${ }^{154}$ While at lower temperature, the morphology of the ZIF-67 nanoparticles is maintained in the carbonized form, at higher temperatures, carbon nanotubes are observed at the surface, whose formation has been catalyzed by the presence of cobalt. At $1200^{\circ} \mathrm{C}$, cobalt form large aggregates, wrapped by sheets of graphitic carbon. Beyond $1600{ }^{\circ} \mathrm{C}$, the morphology was primarily that of hollow carbon onions. The sample that had been pyrolyzed at $800{ }^{\circ} \mathrm{C}$, i.e., Co@C-800, shows an excellent ORR activity with an onset potential of $0.92 \mathrm{~V}$ ( $v s$. RHE), along with a 4 electron transfer pathway and excellent stability. This stability can be attributed 

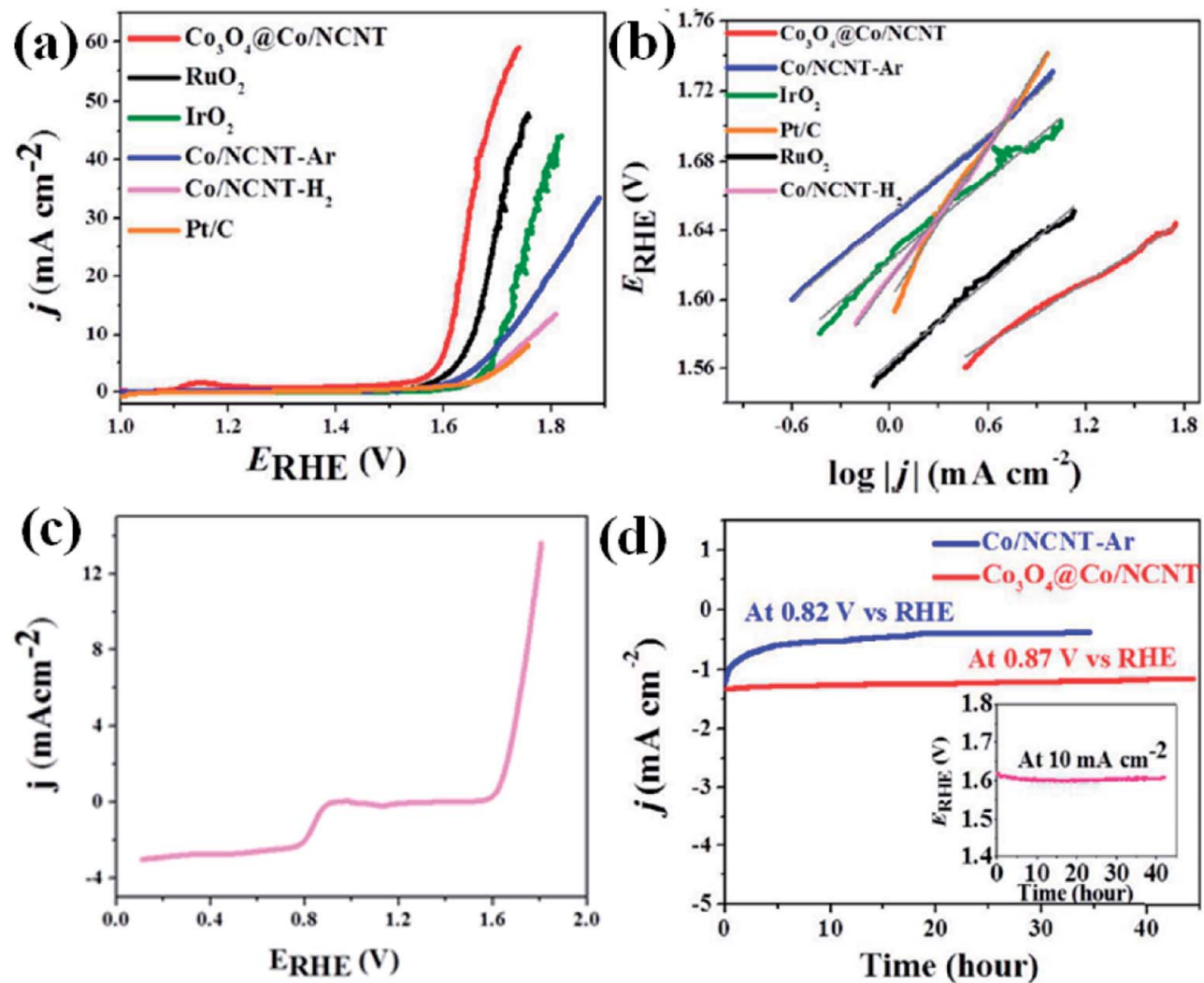

Fig. 16 (a) iR-corrected linear sweep voltammograms of different electrocatalysts at 1600 rpm; (b) corresponding OER Tafel plots; (c) iRcorrected LSV recorded at 1600 rpm showing bifunctional activity of $\mathrm{CO}_{3} \mathrm{O}_{4}$ @Co/NCNT; (d) chronoamperometric stability of Co/NCNT-Ar and $\mathrm{CO}_{3} \mathrm{O}_{4} \mathrm{aCo} / \mathrm{NCNT}$; inset shows chronopotentiometric stability of $\mathrm{CO}_{3} \mathrm{O}_{4} \mathrm{aCo} / \mathrm{NCNT}$ at $10 \mathrm{~mA} \mathrm{cma} 2$ at $1600 \mathrm{rpm}$. Reproduced with permission from ref. 121. Copyright 2017 Wiley.

to the protection of the Co nanoparticles by the layers of carbon matrix. Moreover, the excellent bifunctionality of Co@C-800 is established upon investigating its role in OER. It showed an onset potential of $1.43 \mathrm{~V}$ and a potential of merely $1.61 \mathrm{~V}$ is required to achieve a current density of $10 \mathrm{~mA} \mathrm{~cm}^{-2}$. In this work, the direct effect of the carbonization temperature on the electrochemical activity has been shown. In case of Co@C-800, Co and $\mathrm{N}$ dopants could induce a positive charge on the adjacent carbon atoms, thereby assisting in the adsorption of $\mathrm{OH}^{-}$ and electron transfer. ${ }^{154}$

MOF derived dual catalysts have been also attempted for HER and OER, thereby showing activity as a catalyst for overall water splitting. A recent work involves the pyrolysis of the zeolitic imidazolate framework ZIF-8 (Zn(MIM) $)_{2}$ ) to generate a N containing porous carbon. Using cathodic polarization treatment (CPT) up to $8 \mathrm{~h}$, the $\mathrm{N}$ and $\mathrm{O}$ containing surface groups are modulated without compromising its large surface area or pore size distribution (Fig. 17(a)). A sample having undergone $6 \mathrm{~h}$ CPT shows an excellent HER activity in $0.5 \mathrm{M} \mathrm{H}_{2} \mathrm{SO}_{4}$ electrolyte with an overpotential of $155 \mathrm{mV}$, a Tafel slope of $54.7 \mathrm{mV} \mathrm{dec}^{-1}$ and an exchange current density of $0.063 \mathrm{~mA} \mathrm{~cm}^{-2}$ (Fig. 17(b)). CPT of $4 \mathrm{~h}$ results in excellent OER activity in $0.1 \mathrm{M} \mathrm{KOH}$ electrolyte with an overpotential of $476 \mathrm{mV}$ and a Tafel slope of $78.5 \mathrm{mV} \mathrm{dec}^{-1}$ (Fig. 17(c)). These carbon electrolyzers successfully run a two-electrode water splitting reaction at a current density of $10 \mathrm{~mA} \mathrm{~cm}{ }^{-2}$ over $8 \mathrm{~h}$ under a potential of $1.82 \mathrm{~V}$ with a Faradaic efficiency of $\sim 99 \%$ in $0.1 \mathrm{M} \mathrm{KOH}$ (Fig. 17(d)). ${ }^{155}$ By careful investigation, it has been found that in this case the presence of oxidized $\mathrm{N}$ and carboxylic $\mathrm{O}$ sites on the surface is specifically effective in improving the HER kinetics as these are the active sites. Although in this case, it has been proven that surface area and pore size are not determining factors, larger ECSA definitely ensures better activity. Moreover, investigation of Raman spectra also showed that higher carbonization time inflicts higher number of defects and severe structural damage to the graphitic carbon matrix, thereby lowering activity. ${ }^{155}$

ZIF-67 because of its large cobalt content is an automatic choice for carbonization. Porous $\mathrm{Co}-\mathrm{P} / \mathrm{NC}$ nanopolyhedrons comprising $\mathrm{CoP}_{x}$ nanoparticles embedded in $\mathrm{N}$ containing $\mathrm{C}$ matrix was prepared by the direct carbonization of ZIF-67, followed by phosphidation. This shows excellent performance in both HER and OER in $0.1 \mathrm{M} \mathrm{KOH}$, with low overpotentials and high current density, showing an activity even better than Pt or $\mathrm{IrO}_{2}$. This superior activity has been attributed to their high specific surface area along with interconnected mesoporosity, good conductivity and the dual effect of doped $\mathrm{CoP}_{x}$ and the Ndopants. ${ }^{156}$ In a similar approach, Sun et al. also grew ZIF-67 on a carbon cloth, followed by subsequent carbonization and phosphidation to yield a Co, $\mathrm{N}$ and $\mathrm{P}$ containing carbon matrix named Co-P/NC/CC. This material shows an excellent HER activity in $1.0 \mathrm{M} \mathrm{KOH}$ with an onset potential of $-0.1 \mathrm{~V} v s$. RHE. It also showed an onset potential of $1.5 \mathrm{~V} v s$. RHE for OER in 
(a) $\mathrm{ZIF}-8$

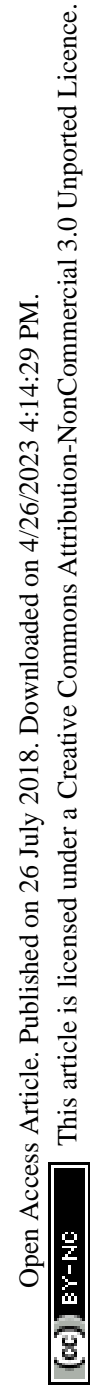

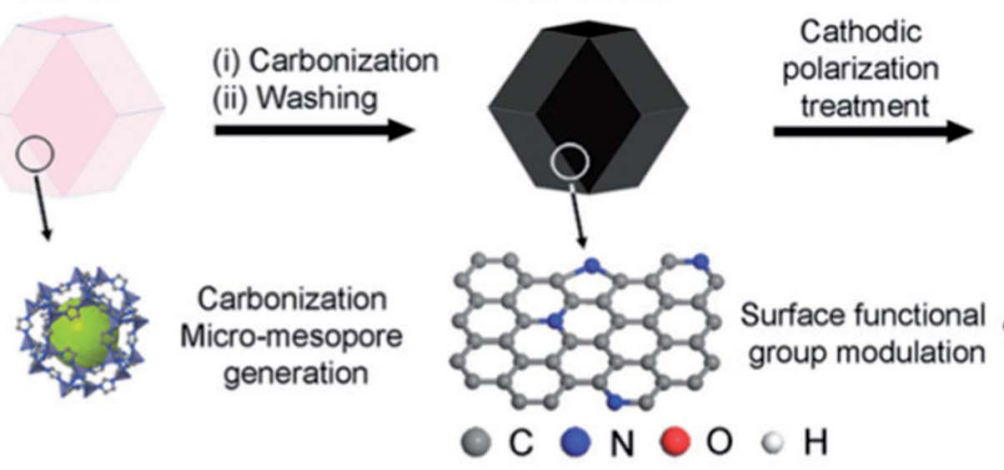

ZIF-8-C2 C8

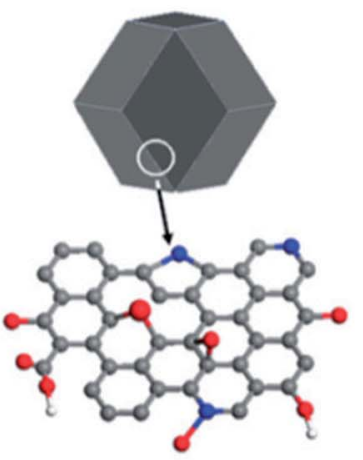

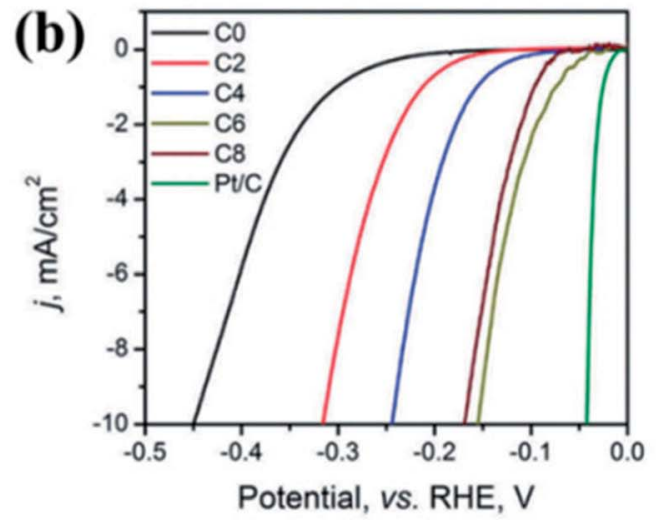
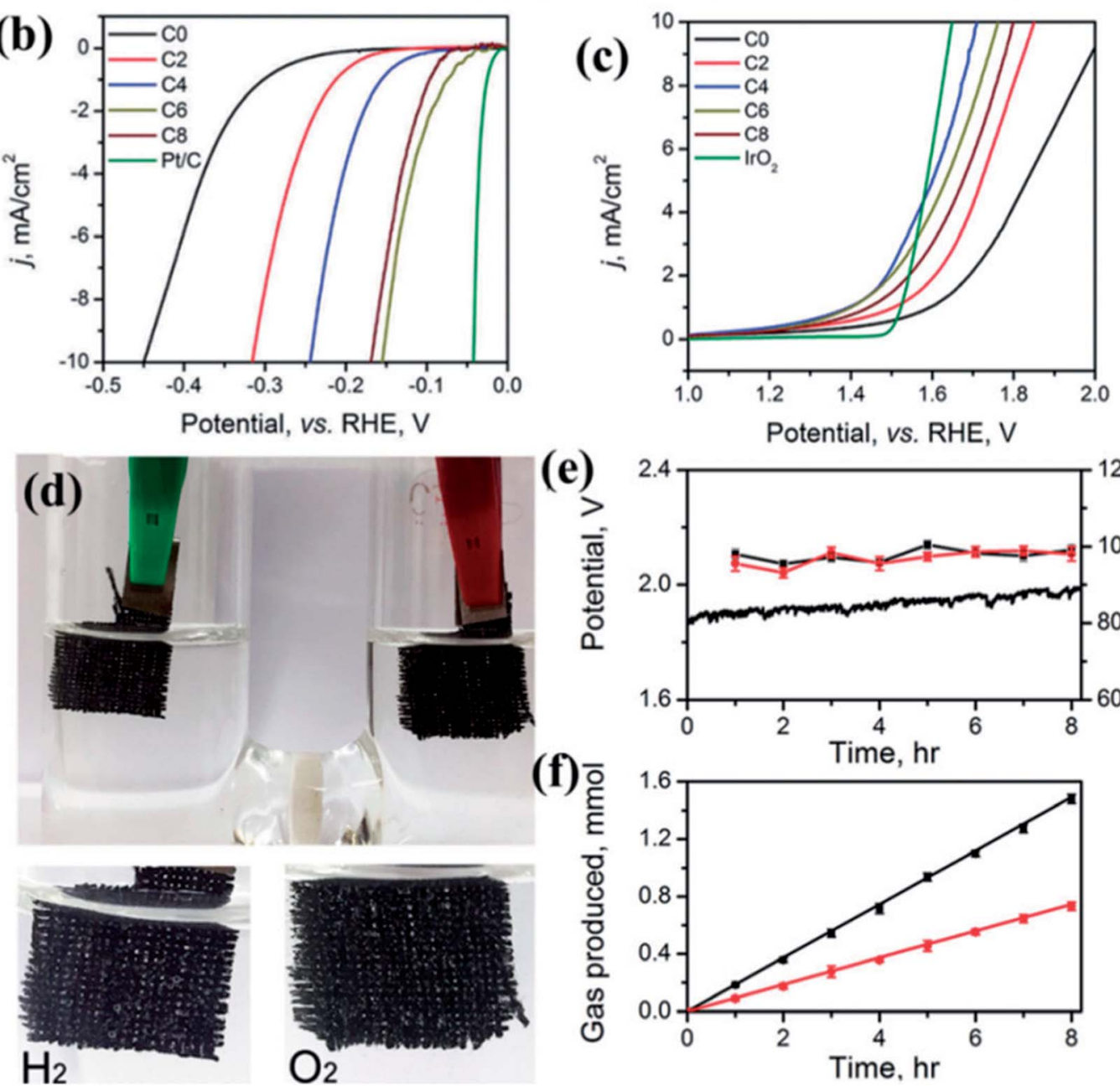

(e)

Potential, vs. RHE, V

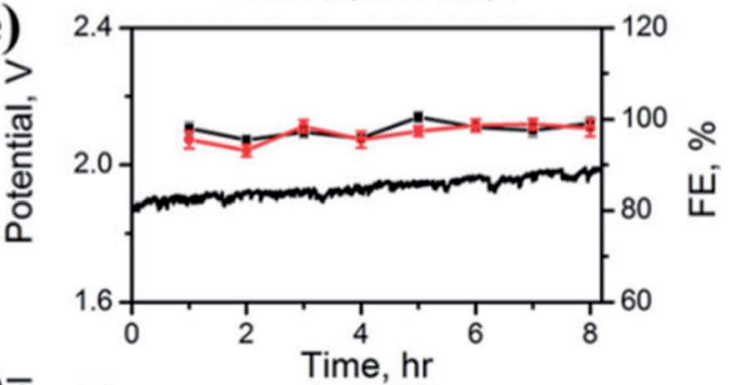

(f)

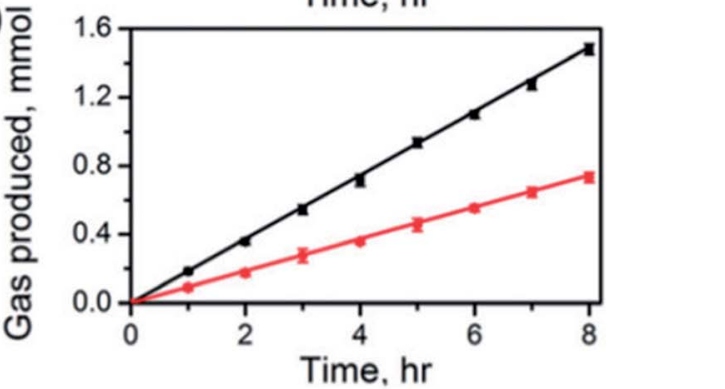

Fig. 17 (a) Schematic representation of the formation of carbon electrocatalysts from ZIF-8. (b) HER LSV polarization and (c) OER LSVs for different carbon samples undergoing CPT for different time durations. (d) Photograph of the electrolyzer performing total water splitting performance of the ZIF-8-C4 at anode and ZIF-8-C6 at cathode in $0.1 \mathrm{M} \mathrm{KOH}$. (e) Water splitting under a current density of $10 \mathrm{~mA} \mathrm{~cm}^{-2}$ for $8 \mathrm{~h}$ and the Faradaic efficiency for HER and OER, respectively. (f) The amount of $\mathrm{H}_{2}$ and $\mathrm{O}_{2}$ released from the electrolyzer was quantified by GC. Reproduced with permission from ref. 155. Copyright 2018 Royal Society of Chemistry.

1.0 $\mathrm{M} \mathrm{KOH}$ and achieves a current density of $10 \mathrm{~mA} \mathrm{~cm}^{-2}$ at an overpotential of merely $330 \mathrm{mV}$. The superior activity of Co-P/ $\mathrm{NC} / \mathrm{CC}$ is not only because of a larger ECSA, but also because the large content of cobalt phosphides. A two-electrode electrolyzer fabricated using this system at cathode and anode in 1.0 $\mathrm{M} \mathrm{KOH}$ for overall water-splitting, where it shows an onset of
1.7 $\mathrm{V}$ and achieves current densities of 10 and $100 \mathrm{~mA} \mathrm{~cm}^{-2}$ at cell voltages of 1.77 and $1.93 \mathrm{~V}$, respectively. ${ }^{162}$

Bifunctionality achieved in mesoporous nitrogen doped graphene (MNG) obtained from ZIF-67 has also been exploited in a multi-functional electrode for $\mathrm{Zn}$-air battery and water splitting device. Here, ZIF-67 has been first grown as fibers on 


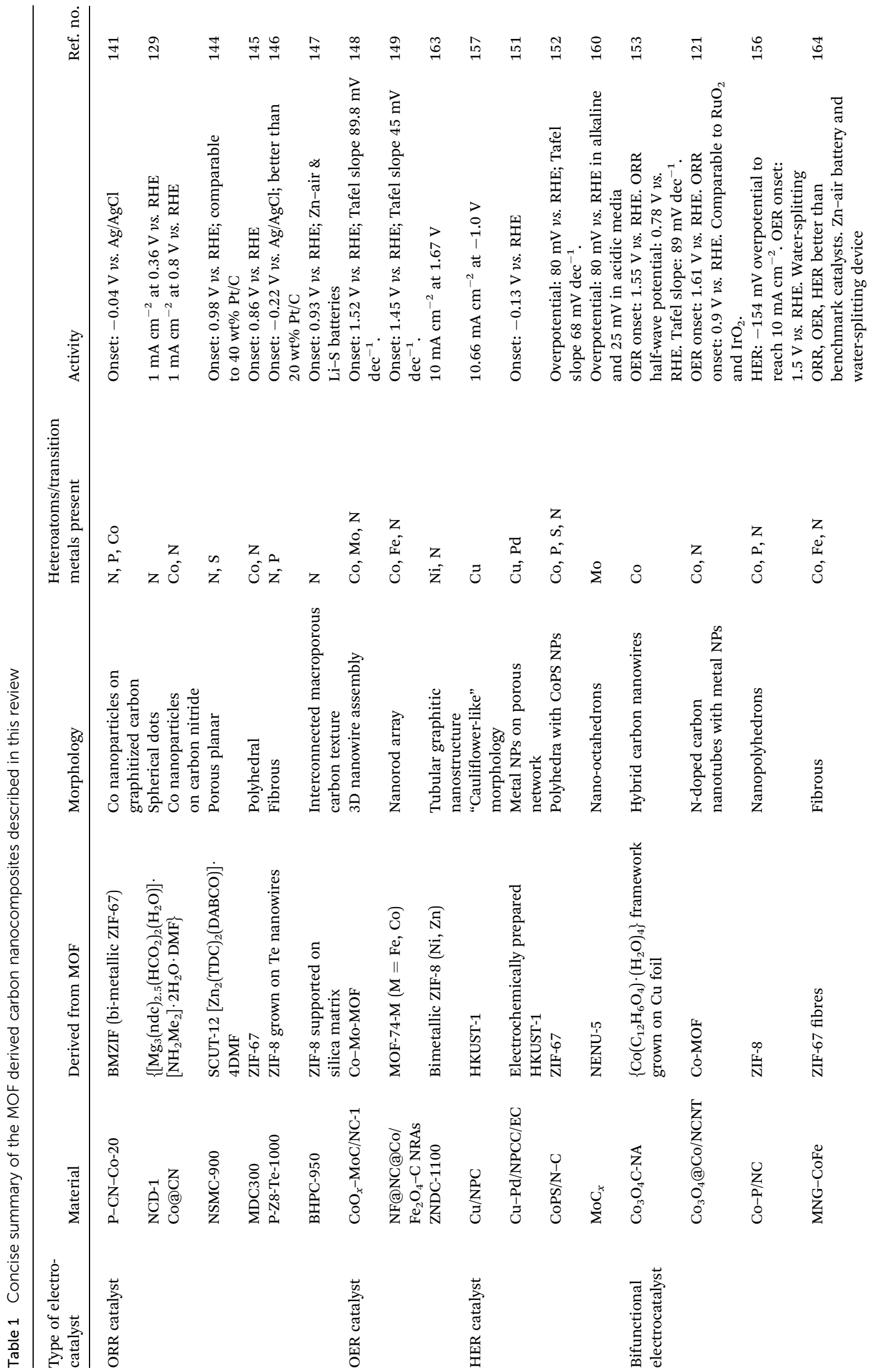


the surface of $\mathrm{NaCl}$ crystals and post carbonization, $\mathrm{NaCl}$ has been washed away with acid, to yield MNG, which has a much higher ECSA than the porous carbon derived from typical polyhedral ZIF-67. MNG-CoFe with encapsulated CoFe alloy nanoparticles showed excellent ORR, OER and HER performances, comparable to benchmark noble metal catalysts. MNG-CoFe when assembled as a multifunctional electrode in the rechargeable $\mathrm{Zn}$-air battery showed high power density and cycling durability. Moreover in a water-splitting device, it showed very low overpotential, outperforming the benchmark catalysts. $^{164}$

Although in most cases, Co and Ni nanoparticles have been exploited for catalysis, $\mathrm{Cu}$ has also been used for bifunctional catalysis. For this purpose, a MOF Cu-NPMOF (containing $\mathrm{Cu}^{2+}$, pyrazine and HEDP = 1-hydroxyethylidene-1,1diphosphonic acid) has been used where $\mathrm{Cu}^{2+}$ is connected by $\mathrm{P}$ containing 1-hydroxyethylidene-1,1-diphosphonic acid (HEDP) and $\mathrm{N}$ containing pyrazine. Upon carbonization, $\mathrm{Cu}_{3} \mathrm{P}$ nanoparticles coated by $\mathrm{N}$ and $\mathrm{P}$-doped carbon shell are formed, which extends to a hierarchical porous carbon matrix ( $\mathrm{Cu}_{3}$ P@NPPC). $\mathrm{Cu}_{3} \mathrm{P} @ \mathrm{NPPC}$ is an excellent catalyst for both HER and OER. ${ }^{165}$

Thus several unique approaches have been adopted to synthesize MOF-derived porous carbon with distinct morphologies and composition showing superior activity. While we have mentioned some over here, many more attempts have been undertaken in this global endeavor of finding cheap alternatives of noble metals for renewable energy technology. The various MOF-derived electrocatalysts that have been discussed in this review has been concisely summarized in Table 1 with their properties and activities.

\section{Conclusions and future perspectives}

This review documents some of the recent research conducted to develop low cost, noble metal-free electrocatalysts derived from MOF. MOFs act as perfect template for generating such carbon materials owing to their innate porosity, stable structure, high carbon content and ease of heteroatom doping. However, the synthesis of efficient carbon based materials requires careful selection of the MOF precursor and the annealing temperature, along with morphology and size control. Till date, quite a few materials have been generated using MOF which are excellent noble metal-free electrocatalysts and have helped in taking a big stride towards cheap alternative catalysts. New and innovative approaches were brought into light which could be utilized to design a plethora of such functional materials. The methodically developed MOF derived materials having favourable electronic structure based on heteroatom doped carbon matrix along with metal or metal compound NPs, can show excellent electrochemical activity. Moreover, suitable morphologies and pore structure that facilitate electron and mass transport are instrumental in developing highly potent electrocatalyst for OER, ORR and HER.
Highly potent MOF-derived carbon-based electrocatalysts can be synthesized by carefully considering the following points:

(1) Careful selection of the MOF is supremely important since ligand composition provides the carbon template with heteroatoms like N, P and S. Similarly, redox-active metal ion from the MOF provides the metal or metal oxide nanoparticles.

(2) Morphology, size and shape of the as synthesized MOF is also crucial as it determines the morphology and corresponding textural parameter of the resultant carbonaceous material.

(3) Pyrolysis temperature and condition are also important parameters which plays a crucial role in determining the morphology and composition of the resultant carbon nanocomposite.

Targeted design and synthesis of tailored MOFs has the potential to develop next-generation materials with superior activity for the commercialization of energy devices like fuel cells and metal-air batteries. Until now, MOF derived functional materials have been exploited as bifunctional catalysts but trifunctional catalysts which can catalyze all the three half reactions-OER, ORR and HER efficiently are yet to be developed from such materials. Such trifunctional materials are ideal for practical use in regenerative fuel cells, electrolyzer, overall water-splitting and metal-air batteries. This missing link can be filled by careful considerations of the design strategies discussed in this review. Thus, this review not only paves way for better understanding of the foundation of designing materials but also throws a challenge to develop an all-in-one trifunctional catalyst from MOF precursor. Another obstacle that needs to be overcome is the poor conductivity of pristine MOFs in order to develop electrochemically active MOFs. Absence of studies that provide a deep insight to the mechanism of the electrocatalytic activities of these materials is also another hurdle in their otherwise steady advancement and this void can be filled by suitable proper theoretical approaches. Additionally, merely the development of new materials is not adequate to fight the global energy demand, sincere efforts to support their application in clean energy technology are also necessary, which would require more rigorous and meticulous performance and stability test. Thus, the challenge is still open to develop electrocatalysts with supreme efficiency and stability along with proper mechanistic insights for successful commercialization of sustainable clean energy techniques.

\section{Conflicts of interest}

There are no conflicts to declare.

\section{Acknowledgements}

S. B. is grateful to INSPIRE Fellowship, Department of Science and Technology, Govt. of India, for fellowship. T. K. M. is grateful to the Department of Science and Technology (DST, Project No. MR-2015/001019 and Project No. TRC-DST/C.14.10/ 16-2724, JNCASR), Govt. of India and JNCASR for financial support. 


\section{References}

1 N. Apergis and J. E. Payne, Energy Econ., 2012, 34, 733.

2 M. Hoel and S. Kverndokk, Resour. Energy Econ., 1996, 18, 115.

3 M. Höök and X. Tang, Energy Policy, 2013, 52, 797.

4 S. Shafiee and E. Topal, Energy Policy, 2009, 37, 181.

5 M. Liserre, T. Sauter and J. Hung, IEEE Ind. Electron. Mag., 2010, 4, 18.

6 I. Dincer, Renewable Sustainable Energy Rev., 2000, 4, 157.

7 R. Baños, F. Manzano-Agugliaro, F. G. Montoya, C. Gil, A. Alcayde and J. Gómez, Renewable Sustainable Energy Rev., 2011, 15, 1753.

8 H. Lund, Energy, 2007, 32, 912.

9 A. Hepbasli, Renewable Sustainable Energy Rev., 2008, 12, 593.

10 C. Zhong, Y. Deng, W. Hu, J. Qiao, L. Zhang and J. Zhang, Chem. Soc. Rev., 2015, 44, 7484.

11 C. Du, J. Yeh and N. Pan, Nanotechnology, 2005, 16, 350.

12 G. Wang, L. Zhang and J. Zhang, Chem. Soc. Rev., 2012, 41, 797.

13 M. Zhi, C. Xiang, J. Li, M. Li and N. Wu, Nanoscale, 2013, 5, 72.

14 X. Su, Q. Wu, J. Li, X. Xiao, A. Lott, W. Lu, B. W. Sheldon and J. Wu, Adv. Energy Mater., 2014, 4, 1300882.

15 L. Ji, Z. Lin, M. Alcoutlabi and X. Zhang, Energy Environ. Sci., 2011, 4, 2682.

16 V. Etacheri, R. Marom, R. Elazari, G. Salitra and D. Aurbach, Energy Environ. Sci., 2011, 4, 3243.

17 L. Carrette, K. A. Friedrich and U. Stimming, Fuel Cells, 2001, 1, 5.

18 S. P. S. Badwal and K. Foger, Ceram. Int., 1996, 22, 257.

19 N. W. DeLuca and Y. A. Elabd, J. Polym. Sci., Part B: Polym. Phys., 2006, 44, 2201.

20 K. G. Gallagher, S. Goebel, T. Greszler, M. Mathias, W. Oelerich, D. Eroglu and V. Srinivasan, Energy Environ. Sci., 2014, 7, 1555.

21 M. Park, H. Sun, H. Lee, J. Lee and J. Cho, Adv. Energy Mater., 2012, 2, 780.

22 F. Cheng and J. Chen, Chem. Soc. Rev., 2012, 41, 2172.

23 J. Suntivich, H. A. Gasteiger, N. Yabuuchi, H. Nakanishi, J. B. Goodenough and Y. Shao-Horn, Nat. Chem., 2011, 3, 546.

24 Z.-L. Wang, D. Xu, J.-J. Xu and X.-B. Zhang, Chem. Soc. Rev., 2014, 43, 7746.

25 Y. Li and H. Dai, Chem. Soc. Rev., 2014, 43, 5257.

26 D. R. Dekel, M. Amar, S. Willdorf, M. Kosa, S. Dhara and C. E. Diesendruck, Chem. Mater., 2017, 29, 4425.

27 L. Ma, S. Chen, Z. Pei, Y. Huang, G. Liang, F. Mo, Q. Yang, J. Su, Y. Gao, J. A. Zapien and C. Zhi, ACS Nano, 2018, 12, 1949.

28 L. Li, J. Yang, H. Yang, L. Zhang, J. Shao, W. Huang, B. Liu and X. Dong, ACS Appl. Energy Mater., 2018, 1, 963.

29 T. An, X. Ge, N. N. Tham, A. Sumboja, Z. Liu and Y. Zong, ACS Sustainable Chem. Eng., 2018, 6, 7743.
30 Q. Liu, Z. Chang, Z. Li and X. Zhang, Small Methods, 2018, 2, 1700231.

31 J. Pan, Y. Y. Xu, H. Yang, Z. Dong, H. Liu and B. Y. Xia, Adv. Sci., 2018, 5, 1700691.

32 L. Carrette, K. A. Friedrich and U. Stimming, Fuel Cells, 2001, 1, 5 .

33 M. A. Laguna-Bercero, R. Campana, A. Larrea, J. A. Kilner and V. M. Orera, Fuel Cells, 2011, 11, 116.

34 J. Pettersson, B. Ramsey and D. Harrison, J. Power Sources, 2006, 157, 28.

35 M. Lefèvre, E. Proietti, F. Jaouen and J.-P. Dodelet, Science, 2009, 324, 71.

36 X. Zhou, J. Qiao, L. Yang and J. Zhang, Adv. Energy Mater., 2014, 4, 1301523.

37 S. S. Dihrab, K. Sopian, M. A. Alghoul and M. Y. Sulaiman, Renewable Sustainable Energy Rev., 2009, 13, 1663.

38 R. J. Gorte, S. Park, J. M. Vohs and C. Wang, Adv. Mater., 2000, 12, 1465.

39 L. Li and A. Manthiram, Adv. Energy Mater., 2016, 6, 1502054.

40 J. Fu, F. M. Hassan, J. Li, D. U. Lee, A. R. Ghannoum, G. Lui, M. A. Hoque and Z. Chen, Adv. Mater., 2016, 28, 6421.

41 J. Zhang, J. Fu, X. Song, G. Jiang, H. Zarrin, P. Xu, K. Li, A. Yu and Z. Chen, Adv. Energy Mater., 2016, 6, 1600476.

42 J.-S. Lee, S. Tai Kim, R. Cao, N.-S. Choi, M. Liu, K. T. Lee and J. Cho, Adv. Energy Mater., 2011, 1, 34.

43 D. U. Lee, H. W. Park, M. G. Park, V. Ismayilov and Z. Chen, ACS Appl. Mater. Interfaces, 2015, 7, 902.

44 S. H. Ahn and A. Manthiram, Small, 2017, 13, 1702068.

45 V. M. Dhavale and S. Kurungot, ACS Catal., 2015, 5, 1445.

46 E. Yoo, T. Okata, T. Akita, M. Kohyama, J. Nakamura and I. Honma, Nano Lett., 2009, 9, 2255.

47 N. M. Marković, T. J. Schmidt, V. Stamenković and P. N. Ross, Fuel Cells, 2001, 1, 105.

48 Z. Peng and H. Yang, J. Am. Chem. Soc., 2009, 131, 7542.

49 V. R. Stamenkovic, B. S. Mun, K. J. J. Mayrhofer, P. N. Ross and N. M. Markovic, J.Am. Chem. Soc., 2006, 128, 8813.

50 Z. Chen, M. Waje, W. Li and Y. Yan, Angew. Chem., Int. Ed., 2007, 46, 4060.

51 D. Wang, H. L. Xin, R. Hovden, H. Wang, Y. Yu, D. A. Muller, F. J. DiSalvo and H. D. Abruña, Nat. Mater., 2013, 12, 81.

52 J. Greeley, I. E. L. Stephens, A. S. Bondarenko, T. P. Johansson, H. A. Hansen, T. F. Jaramillo, J. Rossmeisl, I. Chorkendorff and J. K. Nørskov, Nat. Chem., 2009, 1, 552.

53 K. Maeda, R. Abe and K. Domen, J. Phys. Chem. C, 2011, 115, 3057.

54 H.-G. Jung, Y. S. Jeong, J.-B. Park, Y.-K. Sun, B. Scrosati and Y. J. Lee, ACS Nano, 2013, 7, 3532.

55 E. Antolini, ACS Catal., 2014, 4, 1426.

56 T. Reier, M. Oezaslan and P. Strasser, ACS Catal., 2012, 2, 1765.

57 Z.-F. Huang, J. Wang, Y. Peng, C.-Y. Jung, A. Fisher and X. Wang, Adv. Energy Mater., 2017, 7, 1700544.

58 M. Chen, L. Wang, H. Yang, S. Zhao, H. Xu and G. Wu, J. Power Sources, 2018, 375, 277. 
59 M. Gong, Y. Li, H. Wang, Y. Liang, J. Z. Wu, J. Zhou, J. Wang, T. Regier, F. Wei and H. Dai, J. Am. Chem. Soc., 2013, 135, 8452.

60 L.-L. Feng, G. Yu, Y. Wu, G.-D. Li, H. Li, Y. Sun, T. Asefa, W. Chen and X. Zou, J. Am. Chem. Soc., 2015, 137, 14023.

61 X. Zou and Y. Zhang, Chem. Soc. Rev., 2015, 44, 5148.

62 Z. Chen, D. Higgins, A. Yu, L. Zhang and J. Zhang, Energy Environ. Sci., 2011, 4, 3167.

63 Y. Shi and B. Zhang, Chem. Soc. Rev., 2016, 45, 1529.

64 K. Shen, X. Chen, J. Chen and Y. Li, ACS Catal., 2016, 6, 5887.

65 H. Liu, Q. He, H. Jiang, Y. Lin, Y. Zhang, M. Habib, S. Chen and L. Song, ACS Nano, 2017, 11, 11574.

66 J. Liang, Y. Jiao, M. Jaroniec and S. Z. Qiao, Angew. Chem., Int. Ed., 2012, 51, 11496.

67 H.-W. Liang, W. Wei, Z.-S. Wu, X. Feng and K. Müllen, J. Am. Chem. Soc., 2013, 135, 16002.

68 Z.-S. Wu, S. Yang, Y. Sun, K. Parvez, X. Feng and K. Müllen, J. Am. Chem. Soc., 2012, 134, 9082.

69 L. Qu, Y. Liu, J.-B. Baek and L. Dai, ACS Nano, 2010, 4, 1321.

70 D. Guo, R. Shibuya, C. Akiba, S. Saji, T. Kondo and J. Nakamura, Science, 2016, 351, 361.

71 J. P. Paraknowitsch and A. Thomas, Energy Environ. Sci., 2013, 6, 2839.

72 Z.-H. Sheng, H.-L. Gao, W.-J. Bao, F.-B. Wang and X.-H. Xia, J. Mater. Chem., 2012, 22, 390.

73 L. Yang, S. Jiang, Y. Zhao, L. Zhu, S. Chen, X. Wang, Q. Wu, J. Ma, Y. Ma and Z. Hu, Angew. Chem., 2011, 123, 7270.

74 C. N. R. Rao, K. Gopalakrishnan and A. Govindaraj, Nano Today, 2014, 9, 324.

75 J. Masa, W. Xia, I. Sinev, A. Zhao, Z. Sun, S. Grützke, P. Weide, M. Muhler and W. Schuhmann, Angew. Chem., Int. Ed., 2014, 53, 8508.

76 G. Maurin, C. Serre, A. Cooper and G. Férey, Chem. Soc. Rev., 2017, 46, 3104.

77 Z.-J. Lin, J. Lü, M. Hong and R. Cao, Chem. Soc. Rev., 2014, 43, 5867.

78 H.-C. "Joe" Zhou and S. Kitagawa, Chem. Soc. Rev., 2014, 43, 5415.

79 N. Stock and S. Biswas, Chem. Rev., 2012, 112, 933.

80 R. B. Getman, Y.-S. Bae, C. E. Wilmer and R. Q. Snurr, Chem. Rev., 2012, 112, 703.

81 G. D. Pirngruber and P. L. Llewellyn, Metal-Organic Frameworks, Wiley-VCH Verlag GmbH \& Co. KGaA, Weinheim, Germany, 2011, p. 99.

82 Y. Lin, C. Kong, Q. Zhang and L. Chen, Adv. Energy Mater., 2017, 7, 1601296.

83 B. Li, H.-M. Wen, W. Zhou and B. Chen, J. Phys. Chem. Lett., 2014, 5, 3468-3479.

84 K. Tan, S. Zuluaga, E. Fuentes, E. C. Mattson, J.-F. Veyan, H. Wang, J. Li, T. Thonhauser and Y. J. Chabal, Nat. Commun., 2016, 7, 13871.

85 B. Liu, W.-P. Wu, L. Hou and Y.-Y. Wang, Chem. Commun., 2014, 50, 8731.

86 L. Li, Q. Chen, Z. Niu, X. Zhou, T. Yang and W. Huang, J. Mater. Chem. C, 2016, 4, 1900.
87 E. A. Dolgopolova and N. B. Shustova, MRS Bull., 2016, 41, 890.

88 L. Zhu, X.-Q. Liu, H.-L. Jiang and L.-B. Sun, Chem. Rev., 2017, 117, 8129.

89 M. Ranocchiari and J. A. van Bokhoven, Phys. Chem. Chem. Phys., 2011, 13, 6388.

90 L. Jiao, Y. Wang, H.-L. Jiang and Q. Xu, Adv. Mater., 2017, 1703663.

91 B. Liu, H. Shioyama, T. Akita and Q. Xu, J. Am. Chem. Soc., 2008, 130, 5390.

92 M. B. Solomon, T. L. Church and D. M. D'Alessandro, CrystEngComm, 2017, 19, 4049.

93 I. Hod, P. Deria, W. Bury, J. E. Mondloch, C.-W. Kung, M. So, M. D. Sampson, A. W. Peters, C. P. Kubiak, O. K. Farha and J. T. Hupp, Nat. Commun., 2015, 6, 8304.

94 N. Kornienko, Y. Zhao, C. S. Kley, C. Zhu, D. Kim, S. Lin, C. J. Chang, O. M. Yaghi and P. Yang, J. Am. Chem. Soc., 2015, 137, 14129.

95 Q. Liu, J. Tian, W. Cui, P. Jiang, N. Cheng, A. M. Asiri and X. Sun, Angew. Chem., 2014, 126, 6828.

96 X. Wang, Y. V. Kolen'ko, X.-Q. Bao, K. Kovnir and L. Liu, Angew. Chem., Int. Ed., 2015, 54, 8188.

97 S. Pandiaraj, H. B. Aiyappa, R. Banerjee and S. Kurungot, Chem. Commun., 2014, 50, 3363.

98 W. Chaikittisilp, K. Ariga and Y. Yamauchi, J. Mater. Chem. A, 2013, 1, 14.

99 J. Duan, S. Chen, M. Jaroniec and S. Z. Qiao, ACS Catal., 2015, 5, 5207.

100 Y. Zheng, Y. Jiao, M. Jaroniec and S. Z. Qiao, Angew. Chem., Int. Ed., 2015, 54, 52.

101 L. Zhang and Z. Xia, J. Phys. Chem. C, 2011, 115, 11170.

102 K.-H. Wu, D.-W. Wang, D.-S. Su and I. R. Gentle, ChemSusChem, 2015, 8, 2772.

103 B. D. Mohapatra, S. P. Mantry, N. Behera, B. Behera, S. Rath and K. S. K. Varadwaj, Chem. Commun., 2016, 52, 10385.

104 J. Zhang, Z. Zhao, Z. Xia and L. Dai, Nat. Nanotechnol., 2015, 10, 444.

105 D. K. Singh, R. N. Jenjeti, S. Sampath and M. Eswaramoorthy, J. Mater. Chem. A, 2017, 5, 6025.

106 C. H. Lee, B. Jun and S. U. Lee, ACS Sustain. Chem. Eng., 2018, 6, 4973.

107 J. Yang, M. Xu, J. Wang, S. Jin and B. Tan, Sci. Rep., 2018, 8, 4200.

108 J. Zhang and L. Dai, ACS Catal., 2015, 5, 7244.

109 M. Park, T. Lee and B.-S. Kim, Nanoscale, 2013, 5, 12255.

110 J. Liu, P. Song, Z. Ning and W. Xu, Electrocatalysis, 2015, 6, 132.

111 S. Zhang, Y. Cai, H. He, Y. Zhang, R. Liu, H. Cao, M. Wang, J. Liu, G. Zhang, Y. Li, H. Liu and B. Li, J. Mater. Chem. A, 2016, 4, 4738.

112 D. Zhao, J.-L. Shui, L. R. Grabstanowicz, C. Chen, S. M. Commet, T. Xu, J. Lu and D.-J. Liu, Adv. Mater., 2014, 26, 1093.

113 P. Zhang, F. Sun, Z. Xiang, Z. Shen, J. Yun and D. Cao, Energy Environ. Sci., 2014, 7, 442.

114 B. Chen, R. Li, G. Ma, X. Gou, Y. Zhu and Y. Xia, Nanoscale, 2015, 7, 20674. 
115 W. Xia, R. Zou, L. An, D. Xia and S. Guo, Energy Environ. Sci., 2015, 8, 568.

116 W. Zhang, Z.-Y. Wu, H.-L. Jiang and S.-H. Yu, J. Am. Chem. Soc., 2014, 136, 14385.

117 H. Zhong, J. Wang, Y. Zhang, W. Xu, W. Xing, D. Xu, Y. Zhang and X. Zhang, Angew. Chem., Int. Ed., 2014, 53, 14235.

118 Q. Lai, Y. Zhao, Y. Liang, J. He and J. Chen, Adv. Funct. Mater., 2016, 26, 8334.

119 L. Zhang, X. Wang, R. Wang and M. Hong, Chem. Mater., 2015, 27, 7610.

120 A. Aijaz, J. Masa, C. Rösler, W. Xia, P. Weide, A. J. R. Botz, R. A. Fischer, W. Schuhmann and M. Muhler, Angew. Chem., Int. Ed., 2016, 55, 4087.

121 N. Sikdar, B. Konkena, J. Masa, W. Schuhmann and T. K. Maji, Chem.-Eur. J., 2017, 23, 18049.

122 S. Pandiaraj, H. B. Aiyappa, R. Banerjee and S. Kurungot, Chem. Commun., 2014, 50, 3363.

123 J.-S. Li, Y.-J. Tang, C.-H. Liu, S.-L. Li, R.-H. Li, L.-Z. Dong, Z.-H. Dai, J.-C. Bao and Y.-Q. Lan, J. Mater. Chem. A, 2016, 4, 1202.

124 J. Liu, D. Zhu, C. Guo, A. Vasileff and S.-Z. Qiao, Adv. Energy Mater., 2017, 7, 1700518.

125 H.-S. Lu, H. Zhang, R. Liu, X. Zhang, H. Zhao and G. Wang, Appl. Surf. Sci., 2017, 392, 402.

126 J.-S. Li, S.-L. Li, Y.-J. Tang, M. Han, Z.-H. Dai, J.-C. Bao and Y.-Q. Lan, Chem. Commun., 2015, 51, 2710.

127 J. Li, Y. Chen, Y. Tang, S. Li, H. Dong, K. Li, M. Han, Y.-Q. Lan, J. Bao and Z. Dai, J. Mater. Chem. A, 2014, 2, 6316.

128 Q. Ren, H. Wang, X.-F. Lu, Y.-X. Tong and G.-R. Li, Adv. Sci., 2018, 5, 1700515.

129 S. Bhattacharyya, B. Konkena, K. Jayaramulu, W. Schuhmann and T. K. Maji, J. Mater. Chem. A, 2017, 5, 13573.

130 P. Du and R. Eisenberg, Energy Environ. Sci., 2012, 5, 6012. 131 X. Zou and Y. Zhang, Chem. Soc. Rev., 2015, 44, 5148.

132 R. Liu, D. Wu, X. Feng and K. Müllen, Angew. Chem., 2010, 122, 2619.

133 K. Gong, F. Du, Z. Xia, M. Durstock and L. Dai, Science, 2009, 323, 760.

134 X. Li, L. Yang, T. Su, X. Wang, C. Sun and Z. Su, J. Mater. Chem. A, 2017, 5, 5000.

135 J. Tang, R. R. Salunkhe, H. Zhang, V. Malgras, T. Ahamad, S. M. Alshehri, N. Kobayashi, S. Tominaka, Y. Ide, J. H. Kim and Y. Yamauchi, Sci. Rep., 2016, 6, 30295.

136 J. Xi, Y. Xia, Y. Xu, J. Xiao and S. Wang, Chem. Commun., 2015, 51, 10479.

137 Y.-Z. Chen, C. Wang, Z.-Y. Wu, Y. Xiong, Q. Xu, S.-H. Yu and H.-L. Jiang, Adv. Mater., 2015, 27, 5010.

138 J. Lu, W. Zhou, L. Wang, J. Jia, Y. Ke, L. Yang, K. Zhou, X. Liu, Z. Tang, L. Li and S. Chen, ACS Catal., 2016, 6, 1045.

139 X. Song, T. K. Kim, H. Kim, D. Kim, S. Jeong, H. R. Moon and M. S. Lah, Chem. Mater., 2012, 24, 3065.

140 P. Zhang, F. Sun, Z. Xiang, Z. Shen, J. Yun and D. Cao, Energy Environ. Sci., 2014, 7, 442.

141 Y.-Z. Chen, C. Wang, Z.-Y. Wu, Y. Xiong, Q. Xu, S.-H. Yu and H.-L. Jiang, Adv. Mater., 2015, 27, 5010.
142 H. Tang, S. Cai, S. Xie, Z. Wang, Y. Tong, M. Pan and X. Lu, Adv. Sci., 2016, 3, 1500265.

143 B. You, N. Jiang, M. Sheng, W. S. Drisdell, J. Yano and Y. Sun, ACS Catal., 2015, 5, 7068.

144 A.-D. Tan, K. Wan, Y.-F. Wang, Z.-Y. Fu and Z.-X. Liang, Catal. Sci. Technol., 2018, 8, 335.

145 W. Xia, J. Zhu, W. Guo, L. An, D. Xia and R. Zou, J. Mater. Chem. A, 2014, 2, 11606.

146 W. Zhang, Z. Y. Wu, H. L. Jiang and S. H. Yu, J. Am. Chem. Soc., 2014, 136, 14385.

147 M. Yang, X. Hu, Z. Fang, L. Sun, Z. Yuan, S. Wang, W. Hong, X. Chen and D. Yu, Adv. Funct. Mater., 2017, 27, 1701971.

148 T. Huang, Y. Chen and J. M. Lee, Small, 2017, 13, 1-8.

149 X. F. Lu, L. F. Gu, J. W. Wang, J. X. Wu, P. Q. Liao and G. R. Li, Adv. Mater., 2017, 29, 1604437.

150 J.-B. Raoof, S. R. Hosseini, R. Ojani, S. Mandegarzad, J.-B. Raoof, S. R. Hosseini, R. Ojani and S. Mandegarzad, Energy, 2015, 90, 1075.

151 S. Mandegarzad, J. B. Raoof, S. R. Hosseini and R. Ojani, Appl. Surf. Sci., 2018, 436, 451.

152 Y. Li, S. Niu, D. Rakov, Y. Wang, M. Cabán-Acevedo, S. Zheng, B. Song and P. Xu, Nanoscale, 2018, 10, 7291.

153 T. Y. Ma, S. Dai, M. Jaroniec and S. Z. Qiao, J. Am. Chem. Soc., 2014, 136, 13925.

154 B. Chen, G. Ma, Y. Zhu and Y. Xia, Sci. Rep., 2017, 7, 5266.

155 Y. Lei, L. Wei, S. Zhai, Y. Wang, H. E. Karahan, X. Chen, Z. Zhou, C. Wang, X. Sui and Y. Chen, Mater. Chem. Front., 2018, 2, 102.

156 B. You, N. Jiang, M. Sheng, S. Gul, J. Yano and Y. Sun, Chem. Mater., 2015, 27, 7636.

157 S. K. Henninger, F. Jeremias, H. Kummer and C. Janiak, Eur. J. Inorg. Chem., 2012, 2625.

158 M. H. Naveen, K. Shim, M. S. A. Hossain, J. H. Kim and Y.-B. Shim, Adv. Energy Mater., 2017, 7, 1602002.

159 T. Huang, Y. Chen and J.-M. Lee, ACS Sustainable Chem. Eng., 2017, 5, 5646.

160 H. B. Wu, B. Y. Xia, L. Yu, X.-Y. Yu and X. W. (D) Lou, Nat. Commun., 2015, 6, 6512.

161 E. V. Perez, C. Karunaweera, I. H. Musselman, K. J. Balkus Jr. and J. P. Ferraris, Processes, 2016, 4, 32.

162 X. Liu, J. Dong, B. You and Y. Sun, RSC Adv., 2016, 6, 73336. 163 S. Gadipelli, Z. Li, T. Zhao, Y. Yang, T. Yildrim and Z. Guo, J. Mater. Chem. A., 2017, 5, 24686.

164 W. Niu and Y. Yang, ACS Appl. Energy Mater., 2018, 1, 2440. 165 R. Wang, X.-Y. Dong, J. Du, J.-Y. Zhao and S.-Q. Zang, Adv. Mater., 2018, 30, 1703711.

166 X.-C. Xie, K.-J. Huang and X. Wu, J. Mater. Chem. A, 2018, 6, 6754.

167 C. A. Downes and S. C. Marinescu, ChemSusChem, 2017, 10, 4374.

168 E. M. Miner, T. Fukushima, D. Sheberla, L. Sun, Y. Surendranath and M. Dinca, Nat. Commun., 2016, 7, 10942.

169 M. Jahan, Q. Bao and K. P. Loh, J. Am. Chem. Soc., 2012, 134, 6707. 